\title{
Global, regional, and national burden of age-related hearing loss from 1990 to 2019
}

\author{
Jinyu Man ${ }^{1,2}$, Hui Chen ${ }^{2,3}$, Tongchao Zhang ${ }^{1,2}$, Xiaolin Yin ${ }^{1,2}$, Xiaorong Yang ${ }^{2,3}$, Ming Lu ${ }^{1,2,3}$ \\ ${ }^{1}$ School of Public Health, Cheeloo College of Medicine, Shandong University, Jinan, China \\ ${ }^{2}$ Clinical Epidemiology Unit, Qilu Hospital of Shandong University, Jinan, China \\ ${ }^{3}$ Clinical Research Center of Shandong University, Qilu Hospital, Cheeloo College of Medicine, Shandong \\ University, Jinan, China
}

Correspondence to: Xiaorong Yang, Ming Lu; email: yangxiaorong@sdu.edu.cn, lvming@sdu.edu.cn Keywords: age-related hearing loss, global burden of disease, DALYs, prevalent cases, temporal trend Received: July 28, $2021 \quad$ Accepted: December 8, $2021 \quad$ Published: December 15, 2021

Copyright: (C) 2021 Man et al. This is an open access article distributed under the terms of the Creative Commons Attribution License (CC BY 3.0), which permits unrestricted use, distribution, and reproduction in any medium, provided the original author and source are credited.

\section{ABSTRACT}

The global distribution and temporal trend of age-related hearing loss (ARHL) are unknown, and we aimed to investigate magnitudes and temporal trends of ARHL burden and its influencing factors at the national, regional, and global levels. Based on the information of Global Burden of Disease Study 2019, we calculated the estimated annual percentage change to quantify the global, regional, and national temporal trends of agestandardized rates (ASRs) of ARHL by gender, age, and severity. The number of prevalent cases and disabilityadjusted life years (DALYs) of ARHL increased from 751.50 million and 22.01 million in 1990 to 1456.66 million and 40.24 million in 2019, respectively. Except for a few countries such as Niger and Burkina Faso, the agestandardized prevalence rate and age-standardized DALYs rate showed a downward trend in most countries and regions. Mild ARHL accounted for the largest proportion in all ARHL, and only mild ARHL showed an upward trend in ASRs. In most regions, the proportion of ARHL disease burden attributable to occupational noise showed a downward trend in the past 30 years. In 2019, ARHL disease burden attributable to occupational noise declined with the increase of socio-demographic index in countries. Although the ASR of ARHL in most parts of the world is declining, the absolute disease burden of ARHL is still heavy. Understanding the real-time disease burden of $A R H L$ and its temporal trend is of great significance for formulating more effective preventive measures and reducing the ARHL burden.

\section{INTRODUCTION}

Hearing loss is a major global health problem concerned by WHO. In 2019, 1570 million people were affected by various degrees of hearing loss, roughly equivalent to one out of every five people with this disease [1]. Age-related hearing loss (ARHL) is a frequently reported chronic health problem in the elderly, accounting for the vast majority of hearing loss [2]. In addition to the impact on communication ability, ARHL can also lead to lots of serious health problems, including mental health problems, Alzheimer's disease, and so on [3]. A full understanding of the temporal trends and its influencing factors of ARHL disease burden is the basis for formulating targeted public policies and reducing the disease burden of the population.

However, most of the current studies only describe the prevalence rate of hearing loss in a country or a region, and few studies describe the global temporal trends and influential factors of the temporal trends of ARHL. The Global Burden of Disease (GBD) study 2019 hearing loss collaborators explored and fully reported the global prevalence of hearing loss from 1990 to 2019 and predicted the prevalence of hearing loss by 2050 , which 
provided a basis for the prevention and control of hearing loss [1]. Marcin Masalski et al. conducted a cross-sectional study using the APP Hearing Test to assess the prevalence of hearing loss in 74 countries [4]. Stevens et al. found that rates of hearing loss in children and adults are much higher in low and middle-income countries than in high-income countries using data from 42 studies carried out between 1970 and 2010 in 29 countries [5]. Occupational noise is also an important factor affecting the incidence of ARHL [3]. However, the temporal trends of ARHL burden and the influence of factors, such as occupational noise, on temporal trends of ARHL disease burden are still unknown. Under the premise of increasing population aging, understanding the temporal trends and its influencing factors of the ARHL disease burden is essential to prioritize effective preventive measures.

GBD study 2019 systematically assesses and updates the disease burden and influencing factors in 204 countries and territories, which provides a unique opportunity to research temporal trends and its influential factors of ARHL disease burden. In this study, we aim to estimate the temporal trends and its influential factors of ARHL disease burden by genders, age groups, and hearing loss severity at global, regional and national levels. Our findings will provide the basis for the allocation of medical resources and policymaking for the reduction of the ARHL disease burden globally.

\section{RESULTS}

\section{The global burden due to ARHL}

Globally, the ARHL patients increased from 751.50 [95\% uncertainty interval (UI): 716.45, 787.33] million in 1990 to 1456.66 (95\% UI: 1395.61, 1519.30) million in 2019, and the age-standardized prevalence rate (ASPR) showed a slight upward trend from 17.33 to 17.76 per 100 during the period, with an estimated annual percentage change (EAPC) of $0.08 \quad$ [95\% confidence interval (CI): 0.07, 0.10]. The estimated disability-adjusted life years (DALYs) of ARHL worldwide increased from 22.01 (95\% UI: 14.91, 31.34) million to 40.24 (95\% UI: $27.39,57.13$ ) million over the past 30 years, with a stable age-standardized DALY rate (ASDR) of about 0.005 . The number of males with ARHL was 742.04 (95\% UI 711.33, 774.94) million in 2019, accounting for $50.9 \%$ of all ARHL patients, causing 20.17 (95\% UI 13.71, 28.75) million DALYs. Although women had lower ASPR and ASDR than men, female ASPR rose faster and ASDR fell more slowly (Table 1). Most patients were between 45-74 years old, and the burden of disease in this age group was also heavier (Figure 1).
Variation in ARHL burden at the national and regional level

The global variety of ASPR and ASDR of ARHL was around 2.4 and 3.5 times in 2019, respectively, with the highest ASPR (21.35/100) and ASDR (6.77/1000) in Kenya, and the lowest ASPR (8.75/100) and ASDR $(1.96 / 1000)$ in Sweden. Overall, the ASPR in 2019 was higher than $17 / 100$ in 98 countries and territories, including China, India, South Africa, etc., (Figure 2A, Supplementary Table 1), which also showed a severe burden in ASDR (Figure 2B, Supplementary Table 1). During the period from 1990 to 2019, 24 countries and territories showed an upward trend in ASPR, including China and the USA. ASDRs in most countries and territories showed a downward trend. Only a very small number of countries and territories, such as Niger and Burkina Faso, show an upward trend both in ASPR and ASDR (Figure 2C, Figure 2D, Supplementary Table 1, Supplementary Table 2). The number of DALYs and prevalent cases was high in high-middle and middle socio-demographic index (SDI) regions and increased in all SDI regions compared with 1990. ASPR and ASDR in other SDI regions showed a downward or stable trend, excluding the rising trend of ASPR in high and high-middle SDI regions (Table 1, Supplementary Figure 1). Except for the ASPR in East Asia, which showed an upward trend, the ASPR and ASDR in other GBD regions showed a downward or stable trend (Supplementary Table 2).

\section{ARHL burden due to severity}

Compared with 1990, the number of DALYs and prevalent cases of ARHL of all severity in 2019 has increased significantly. Among them, the number of DALYs and prevalent cases of mild ARHL was the highest, 10.28 (95\% UI: 4.57, 19.82) million and 1083.06 (95\% UI: $1029.88, \quad 1136.29)$ million respectively, which almost doubled from 1990. The ASPR and ASDR of all other severity ARHL were lower than $0.1 / 1000$ and 5/100, and both showed a downward trend, except for mild ARHL. The ASDR and ASPR of mild ARHL were $0.12 / 1000$ and $13.09 / 100$ in 2019, respectively, and both showed an upward trend, with EAPC of 0.18 and 0.18 respectively (Table 1). In terms of age distribution, people over 75 years old account for a larger proportion of moderate/moderately severe/severe ARHL, and people under 49 years old account for a larger proportion of profound/complete ARHL (Supplementary Figure 2). Except for the DALY rate of mild ARHL and the moderately severe ARHL of the age group over 70 years old, which showed a slight increase, the DALY rate of ARHL of each severity of all age groups showed a downward trend or remained unchanged 
Table 1. Age-related hearing loss prevalent cases and burden in 1990 and 2019 and the temporal trends from 1990 to 2019.

\begin{tabular}{|c|c|c|c|c|c|c|c|c|c|c|}
\hline \multirow{4}{*}{$\begin{array}{l}\text { Characteri } \\
\text { stics }\end{array}$} & \multicolumn{4}{|c|}{1990} & \multicolumn{4}{|c|}{2019} & \multicolumn{2}{|c|}{ EAPC (1990-2019) } \\
\hline & \multicolumn{2}{|c|}{ Prevalent cases } & \multicolumn{2}{|c|}{ DALYs } & \multicolumn{2}{|c|}{ Prevalent cases } & \multicolumn{2}{|c|}{ DALYs } & \multirow[t]{2}{*}{ ASPR } & \multirow[t]{2}{*}{ ASDR } \\
\hline & & ASPR & & ASDR & & ASPR & & ASDR & & \\
\hline & $\begin{array}{l}\text { No. } \times 10^{6} \\
(95 \% \text { UI) }\end{array}$ & $\begin{array}{l}\text { No. } \times 10^{-2} \\
(95 \% \text { UI })\end{array}$ & $\begin{array}{l}\text { No. } \times 10^{6} \\
(95 \% \text { UI }) \\
\end{array}$ & $\begin{array}{l}\text { No. } \times 10^{-3} \\
(95 \% \text { UI }) \\
\end{array}$ & $\begin{array}{l}\text { No. } \times 10^{6} \\
(95 \% \text { UI) }\end{array}$ & $\begin{array}{l}\text { No. } \times 10^{-2} \\
(95 \% \text { UI })\end{array}$ & $\begin{array}{l}\text { No. } \times 10^{6} \\
(95 \% \text { UI) } \\
\end{array}$ & $\begin{array}{l}\text { No. } \times 10^{-3} \\
(95 \% \text { UI })\end{array}$ & $\begin{array}{c}\text { No. } \\
(95 \% \text { CI }) \\
\end{array}$ & $\begin{array}{c}\text { No. } \\
(95 \% \text { CI }) \\
\end{array}$ \\
\hline Global & $\begin{array}{c}751.50 \\
(716.45,787.33)\end{array}$ & $\begin{array}{c}17.33 \\
(16.58,18.10)\end{array}$ & $\begin{array}{c}22.01 \\
(14.91,31.34)\end{array}$ & $\begin{array}{c}5.09 \\
(3.47,7.25)\end{array}$ & $\begin{array}{c}1456.66 \\
(1395.61,1519.30)\end{array}$ & $\begin{array}{c}17.76 \\
(17.01,18.52)\end{array}$ & $\begin{array}{c}40.24 \\
(27.39,57.13)\end{array}$ & $\begin{array}{c}4.99 \\
(3.40,7.10)\end{array}$ & $\begin{array}{c}0.08 \\
(0.07,0.10)^{*}\end{array}$ & $\begin{array}{c}-0.07 \\
(-0.09,-0.05)\end{array}$ \\
\hline \multicolumn{11}{|l|}{ Sex } \\
\hline Males & $\begin{array}{c}386.11 \\
(367.62,405.17)\end{array}$ & $\begin{array}{c}18.49 \\
(17.68,19.33)\end{array}$ & $\begin{array}{c}11.11 \\
(7.44,15.88)\end{array}$ & $\begin{array}{c}5.40 \\
(3.67,7.70)\end{array}$ & $\begin{array}{c}742.04 \\
(711.33,774.94)\end{array}$ & $\begin{array}{c}18.74 \\
(17.98,19.56)\end{array}$ & $\begin{array}{c}20.17 \\
(13.71,28.75)\end{array}$ & $\begin{array}{c}5.24 \\
(3.57,7.46)\end{array}$ & $\begin{array}{c}0.05 \\
(0.04,0.06)^{*}\end{array}$ & $\begin{array}{c}-0.10 \\
(-0.12,-0.08)\end{array}$ \\
\hline Females & $\begin{array}{c}365.39 \\
(348.73,381.94)\end{array}$ & $\begin{array}{c}16.24 \\
(15.53,16.95)\end{array}$ & $\begin{array}{c}10.90 \\
(7.47,15.46)\end{array}$ & $\begin{array}{c}4.80 \\
(3.29,6.82)\end{array}$ & $\begin{array}{c}714.62 \\
(685.19,745.32)\end{array}$ & $\begin{array}{c}16.81 \\
(16.11,17.52)\end{array}$ & $\begin{array}{c}20.07 \\
(13.64,28.40)\end{array}$ & $\begin{array}{c}4.76 \\
(3.24,6.76)\end{array}$ & $\begin{array}{c}0.12 \\
(0.11,0.13)^{*}\end{array}$ & $\begin{array}{c}-0.05 \\
(-0.07,-0.03)\end{array}$ \\
\hline \multicolumn{11}{|l|}{ Severity } \\
\hline $\begin{array}{l}\text { Mild } \\
\text { hearing loss }\end{array}$ & $\begin{array}{c}553.35 \\
(523.49,583.60)\end{array}$ & $\begin{array}{c}12.48 \\
(11.83,13.10)\end{array}$ & $\begin{array}{c}5.25 \\
(2.34,10.09)\end{array}$ & $\begin{array}{c}0.12 \\
(0.05, .23)\end{array}$ & $\begin{array}{c}1083.06 \\
(1029.88,1136.29)\end{array}$ & $\begin{array}{c}13.09 \\
(12.44,13.74)\end{array}$ & $\begin{array}{c}10.28 \\
(4.57,19.82)\end{array}$ & $\begin{array}{c}0.12 \\
(0.06,0.24)\end{array}$ & $\begin{array}{c}0.18 \\
(0.17,0.19)^{*}\end{array}$ & $\begin{array}{c}0.18 \\
(0.17,0.19)^{*}\end{array}$ \\
\hline $\begin{array}{l}\text { Moderate } \\
\text { hearing loss }\end{array}$ & $\begin{array}{c}126.66 \\
(109.55,144.62)\end{array}$ & $\begin{array}{c}3.14 \\
(2.75,3.56)\end{array}$ & $\begin{array}{c}3.32 \\
(1.90,5.36)\end{array}$ & $\begin{array}{c}0.08 \\
(0.05,0.13)\end{array}$ & $\begin{array}{c}245.98 \\
(214.76,278.22)\end{array}$ & $\begin{array}{c}3.05 \\
(2.67,3.44)\end{array}$ & $\begin{array}{c}6.45 \\
(3.70,10.47)\end{array}$ & $\begin{array}{c}0.08 \\
(0.05,0.13)\end{array}$ & $\begin{array}{c}-0.17 \\
(-0.21,-0.13)\end{array}$ & $\begin{array}{c}-0.17 \\
(-0.21,-0.12)\end{array}$ \\
\hline $\begin{array}{l}\text { Moderately } \\
\text { severe } \\
\text { hearing loss }\end{array}$ & $\begin{array}{c}43.24 \\
(35.89,51.86)\end{array}$ & $\begin{array}{c}1.09 \\
(0.92,1.31)\end{array}$ & $\begin{array}{c}3.91 \\
(2.53,5.73)\end{array}$ & $\begin{array}{c}0.10 \\
(0.06,0.14)\end{array}$ & $\begin{array}{c}82.75 \\
(69.07,99.54)\end{array}$ & $\begin{array}{c}1.05 \\
(0.88,1.25)\end{array}$ & $\begin{array}{c}7.47 \\
(4.86,10.89)\end{array}$ & $\begin{array}{c}0.09 \\
(0.06,0.14)\end{array}$ & $\begin{array}{c}-0.11 \\
(-0.14,-0.09)\end{array}$ & $\begin{array}{c}-0.11 \\
(-0.13,-0.08)\end{array}$ \\
\hline $\begin{array}{l}\text { Severe } \\
\text { hearing loss }\end{array}$ & $\begin{array}{c}9.86 \\
(7.24,12.73)\end{array}$ & $\begin{array}{c}0.23 \\
(0.18,0.30)\end{array}$ & $\begin{array}{c}1.52 \\
(0.90,2.31)\end{array}$ & $\begin{array}{c}0.04 \\
(0.02,0.05)\end{array}$ & $\begin{array}{c}17.43 \\
(13.40,22.10)\end{array}$ & $\begin{array}{c}0.22 \\
(0.17,0.28)\end{array}$ & $\begin{array}{c}2.69 \\
(1.62,4.02)\end{array}$ & $\begin{array}{c}0.03 \\
(0.02,0.05)\end{array}$ & $\begin{array}{c}-0.18 \\
(-0.22,-0.13)\end{array}$ & $\begin{array}{c}-0.17 \\
(-0.21,-0.13)\end{array}$ \\
\hline $\begin{array}{l}\text { Profound } \\
\text { hearing loss }\end{array}$ & $\begin{array}{c}10.52 \\
(7.97,13.57)\end{array}$ & $\begin{array}{c}0.21 \\
(0.17,0.27)\end{array}$ & $\begin{array}{c}2.11 \\
(1.29,3.22)\end{array}$ & $\begin{array}{c}0.04 \\
(0.03,0.06)\end{array}$ & $\begin{array}{c}15.89 \\
(12.36,20.10)\end{array}$ & $\begin{array}{c}0.20 \\
(0.16,0.26)\end{array}$ & $\begin{array}{c}3.18 \\
(2.00,4.73)\end{array}$ & $\begin{array}{c}0.04 \\
(0.03,0.06)\end{array}$ & $\begin{array}{c}-0.20 \\
(-0.23,-0.17)\end{array}$ & $\begin{array}{c}-0.19 \\
(-0.22,-0.17)\end{array}$ \\
\hline $\begin{array}{l}\text { Complete } \\
\text { hearing loss }\end{array}$ & $\begin{array}{c}7.87 \\
(5.88,10.03)\end{array}$ & $\begin{array}{c}0.17 \\
(0.13,0.22)\end{array}$ & $\begin{array}{c}1.66 \\
(0.99,2.52)\end{array}$ & $\begin{array}{c}0.04 \\
(0.02,0.05)\end{array}$ & $\begin{array}{c}11.54 \\
(9.05,14.35)\end{array}$ & $\begin{array}{c}0.15 \\
(0.12,0.18)\end{array}$ & $\begin{array}{c}2.42 \\
(1.52,3.65)\end{array}$ & $\begin{array}{c}0.03 \\
(0.02,0.05)\end{array}$ & $\begin{array}{c}-0.59 \\
(-0.62,-0.56)\end{array}$ & $\begin{array}{c}-0.59 \\
(-0.62,-0.56)\end{array}$ \\
\hline \multicolumn{11}{|l|}{ SDI region } \\
\hline High & $\begin{array}{c}128.53 \\
(121.99,135.28)\end{array}$ & $\begin{array}{c}12.90 \\
(12.27,13.56)\end{array}$ & $\begin{array}{c}3.69 \\
(2.52,5.26)\end{array}$ & $\begin{array}{c}3.70 \\
(2.52,5.28)\end{array}$ & $\begin{array}{c}212.17 \\
(201.03,223.56)\end{array}$ & $\begin{array}{c}12.99 \\
(12.35,13.64)\end{array}$ & $\begin{array}{c}6.09 \\
(4.14,8.64)\end{array}$ & $\begin{array}{c}3.60 \\
(2.45,5.16)\end{array}$ & $\begin{array}{c}0.01 \\
(0.00,0.02)^{*}\end{array}$ & $\begin{array}{c}-0.07 \\
(-0.08,-0.06)\end{array}$ \\
\hline $\begin{array}{l}\text { High- } \\
\text { middle }\end{array}$ & $\begin{array}{c}190.15 \\
(181.89,198.78)\end{array}$ & $\begin{array}{c}17.18 \\
(16.44,17.94)\end{array}$ & $\begin{array}{c}5.29 \\
(3.58,7.55)\end{array}$ & $\begin{array}{c}4.90 \\
(3.32,6.99)\end{array}$ & $\begin{array}{c}338.17 \\
(324.11,352.67)\end{array}$ & $\begin{array}{c}17.70 \\
(16.97,18.45)\end{array}$ & $\begin{array}{c}8.93 \\
(6.04,12.80)\end{array}$ & $\begin{array}{c}4.78 \\
(3.26,6.80)\end{array}$ & $\begin{array}{c}0.12 \\
(0.10,0.13)^{*}\end{array}$ & $\begin{array}{c}-0.08 \\
(-0.11,-0.06)\end{array}$ \\
\hline Middle & $\begin{array}{c}239.59 \\
(228.42,251.13)\end{array}$ & $\begin{array}{c}19.45 \\
(18.63,20.27)\end{array}$ & $\begin{array}{c}6.97 \\
(4.68,9.94)\end{array}$ & $\begin{array}{c}5.69 \\
(3.90,8.09)\end{array}$ & $\begin{array}{c}498.57 \\
(478.56,519.76)\end{array}$ & $\begin{array}{c}19.37 \\
(18.60,20.15)\end{array}$ & $\begin{array}{c}13.23 \\
(8.95,18.86)\end{array}$ & $\begin{array}{c}5.36 \\
(3.67,7.62)\end{array}$ & $\begin{array}{c}0.00 \\
(-0.02,0.01)\end{array}$ & $\begin{array}{c}-0.21 \\
(-0.23,-0.18)\end{array}$ \\
\hline $\begin{array}{l}\text { Low- } \\
\text { middle }\end{array}$ & $\begin{array}{c}138.84 \\
(131.59,146.73)\end{array}$ & $\begin{array}{c}19.05 \\
(18.22,19.92)\end{array}$ & $\begin{array}{c}4.25 \\
(2.86,6.02)\end{array}$ & $\begin{array}{c}5.74 \\
(3.96,8.13)\end{array}$ & $\begin{array}{c}287.32 \\
(274.41,300.34)\end{array}$ & $\begin{array}{c}18.98 \\
(18.21,19.82)\end{array}$ & $\begin{array}{c}8.15 \\
(5.54,11.62)\end{array}$ & $\begin{array}{c}5.47 \\
(3.74,7.74)\end{array}$ & $\begin{array}{c}-0.02 \\
(-0.03,0.00)\end{array}$ & $\begin{array}{c}-0.21 \\
(-0.24,-0.18)\end{array}$ \\
\hline Low & $\begin{array}{c}53.98 \\
(50.78,57.46) \\
\end{array}$ & $\begin{array}{c}17.69 \\
(16.91,18.51)\end{array}$ & $\begin{array}{c}1.80 \\
(1.21,2.53) \\
\end{array}$ & $\begin{array}{c}5.62 \\
(3.86,7.93)\end{array}$ & $\begin{array}{c}119.65 \\
(112.82,127.05)\end{array}$ & $\begin{array}{c}17.53 \\
(16.80,18.30)\end{array}$ & $\begin{array}{c}3.82 \\
(2.58,5.40)\end{array}$ & $\begin{array}{c}5.37 \\
(3.71,7.59) \\
\end{array}$ & $\begin{array}{c}-0.03 \\
(-0.04,-0.02)\end{array}$ & $\begin{array}{c}-0.18 \\
(-0.21,-0.16)\end{array}$ \\
\hline
\end{tabular}

(Supplementary Figure 3A). Except for the increase in DALY rate attributable to occupational noise for males aged 15-49 in the high/high middle SDI region, the DALY rate attributable to occupational noise of males in all age groups and SDI regions was decreasing. The DALY rate attributable to occupational noise for females aged 15-49 in all SDI regions and females over 50 in high/high-middle SDI regions was increasing (Supplementary Figure 3B).

\section{The influential factors for EAPC}

Figure 3 shows the impact of the ASDR in 1990 and SDI in 2019 on ASDR trends in each region. There was no significant correlation between ASDR of ARHL in 1990 and EAPC of ASDR from 1990 to 2019 at the national level $(\rho=0.0529, P=0.4516)$, indicating that ARHL burden may not be given priority intervention in countries with high burden rates. Compared with other countries, some countries with a medium disease burden, such as Egypt, Iran, had a faster decline in disease burden (Figure 3A). Similarly, the temporal trend of ARHL related ASDR from 1990 to 2019 and SDI in 2019 still seemed to have no significant associations at the national level ( $\rho$ $=-0.0287, P=0.6391)$. Some countries in North Africa and Middle East had the most obvious downward trend, despite their varying SDI in 2019 (Figure 3B). In terms of ASPR, we found a positive correlation between the ASPR in 1990 and the EAPC of ASPR from 1990 to 2019 at the national level ( $\rho=$ 0.2437, $P=0.0004$ ) (Supplementary Figure 4). Further, we investigated the correlation between SDI and ASDR by severity from 1990 to 2019 in 21 GBD regions around the world. The results showed that, except for the burden of mild ARHL, which showed a significant upward trend with the increase of SDI, the ASDR of ARHL in other severity was significantly negatively correlated with SDI in the 21 GBD regions (Supplementary Figure 5). 

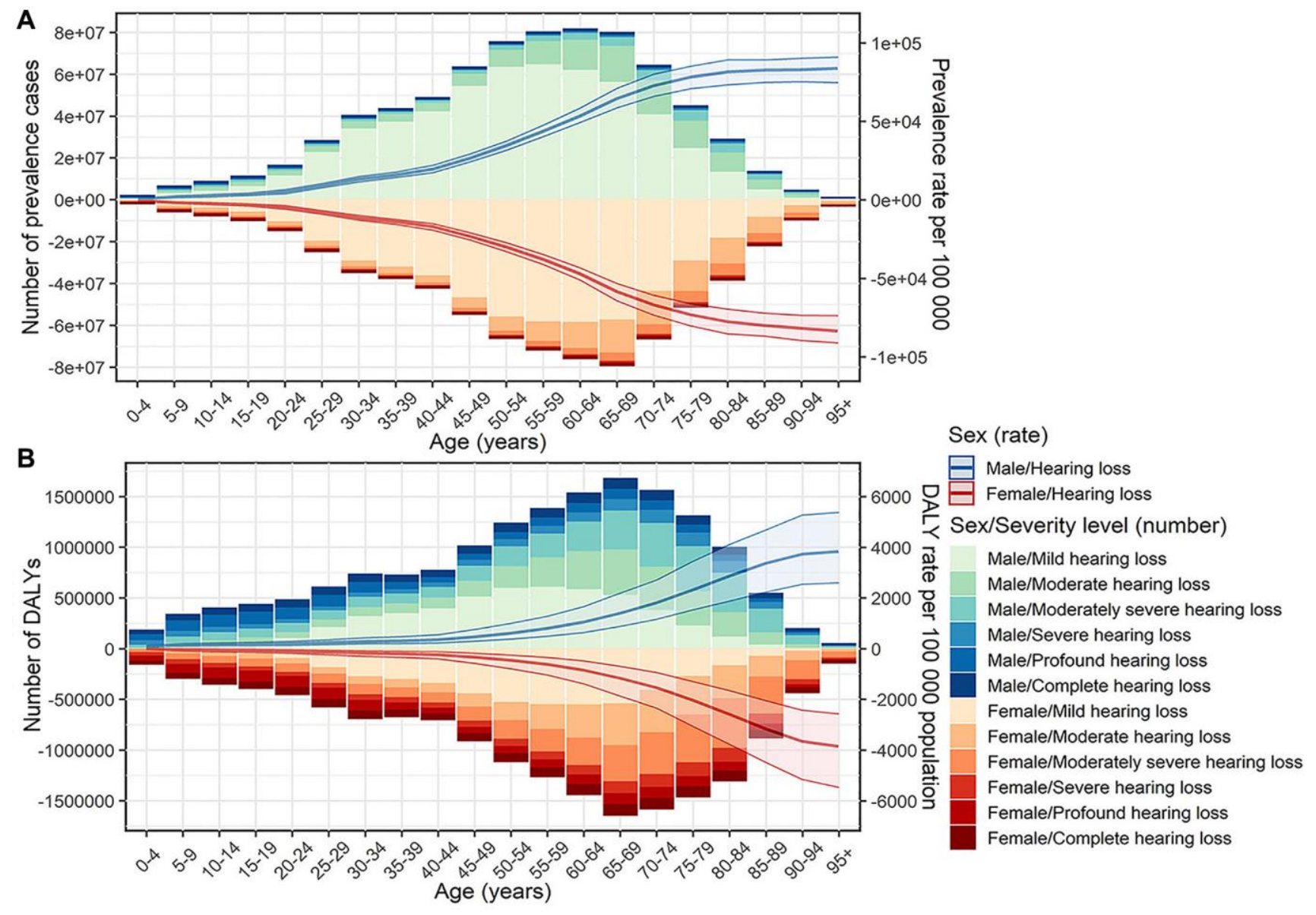

Figure 1. Prevalent cases, DALYs and the corresponding rates of age-related hearing loss by sex, age group, and severity in 2019. (A) Prevalent cases and prevalence rate; (B) DALYs and DALY rate. Abbreviation: DALY: disability-adjusted life year.

A

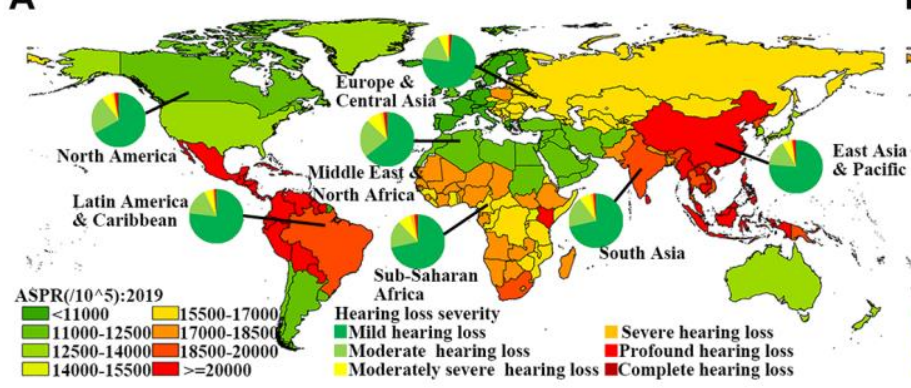

B

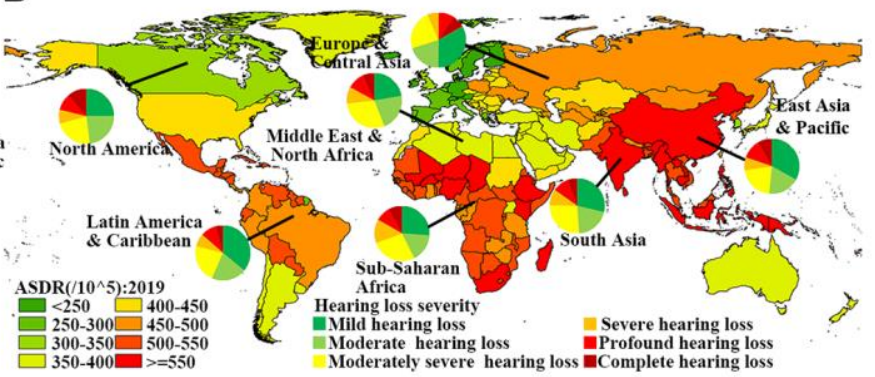

C

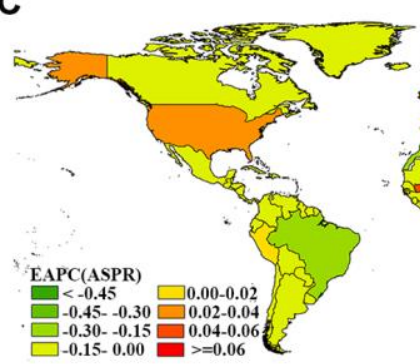

D

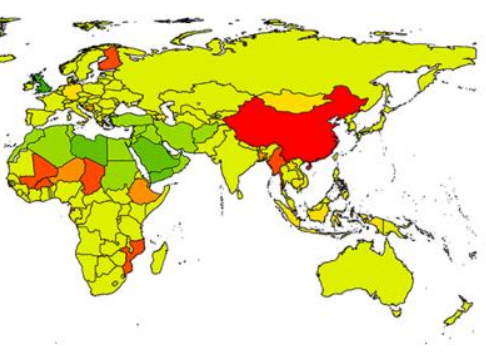

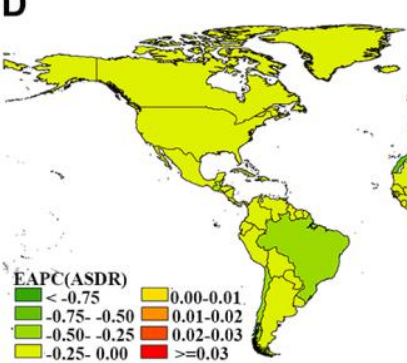

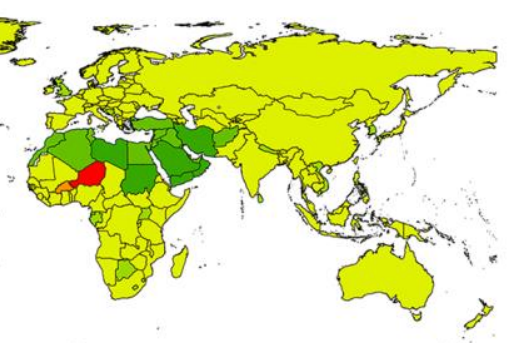

Figure 2. Global distribution of ASRs and the corresponding EAPCs in age-related hearing loss. (A) ASPR in 2019; (B) ASDR in 2019; (C) EAPC of ASPR from 1990 to 2019; (D) EAPC of ASDR from 1990 to 2019. Abbreviations: ASR: age-standardized rate; EAPC: estimated annual percentage change; ASPR: age-standardized prevalence rate; ASDR: age-standardized DALY rate; DALY: disability-adjusted life year. 


\section{The influential factors for ARHL burden attributable to occupational noise}

Among 204 countries and territories, the ASDR attributable to occupational noise in most countries in 2019 was lower than that in 1990 and countries with increased disease burden due to occupational noise were mostly in East Asia and Latin America and Caribbean (Figure 4A). With the increase in SDI in 2019, the ASDR attributed to occupational noise in 2019 was declining at the national level $(\rho=-0.7662, P<2.2 \mathrm{e}$ 16), which reflected the countries with higher SDI levels may be better able to reduce the burden of ARHL (Figure 4B). Similar results were observed in the aspects of the proportion of ARHL burden attributable to occupational noise (Supplementary Figure 6).

\section{DISCUSSION}

Our study summarized the ARHL disease burden by gender, age groups, and severity at the global, regional, and national levels, and further discuss the temporal trends and the influencing factors over the past three decades. Overall, the number of ARHL prevalent cases and DALYs in the world nearly doubled from 1990 to 2019. The ASPR of 24 countries and territories is on the rise, and some of them have large populations, such as the USA and China. The ASDR of most countries and territories shows a downward trend. Mild ARHL accounted for the largest proportion of all ARHL, and only mild ARHL showed an upward trend in ASDR and ASPR. The proportion of ASDR attributed to occupational noise was on the decline in most regions, and with the increase of SDI, the proportion of ASDR attributed to occupational noise was on the decline.

In the past 30 years, the disease burden of ARHL has almost doubled. In 2019, the number of ARHL cases worldwide reached 1456.66 million, which is equivalent to almost one in every five people suffering from ARHL. From 1990 to 2019, the number of people over the age of 30 in the world increased from 2157.4 million to 3825.4 million, almost doubling, however, the number of people under the age of 30 changed slightly (from 3237.4 million to 3815.1 million) [6]. The aging population and the higher prevalence rate of ARHL among people over 45 years old may be the reasons for the nearly doubled prevalent cases of
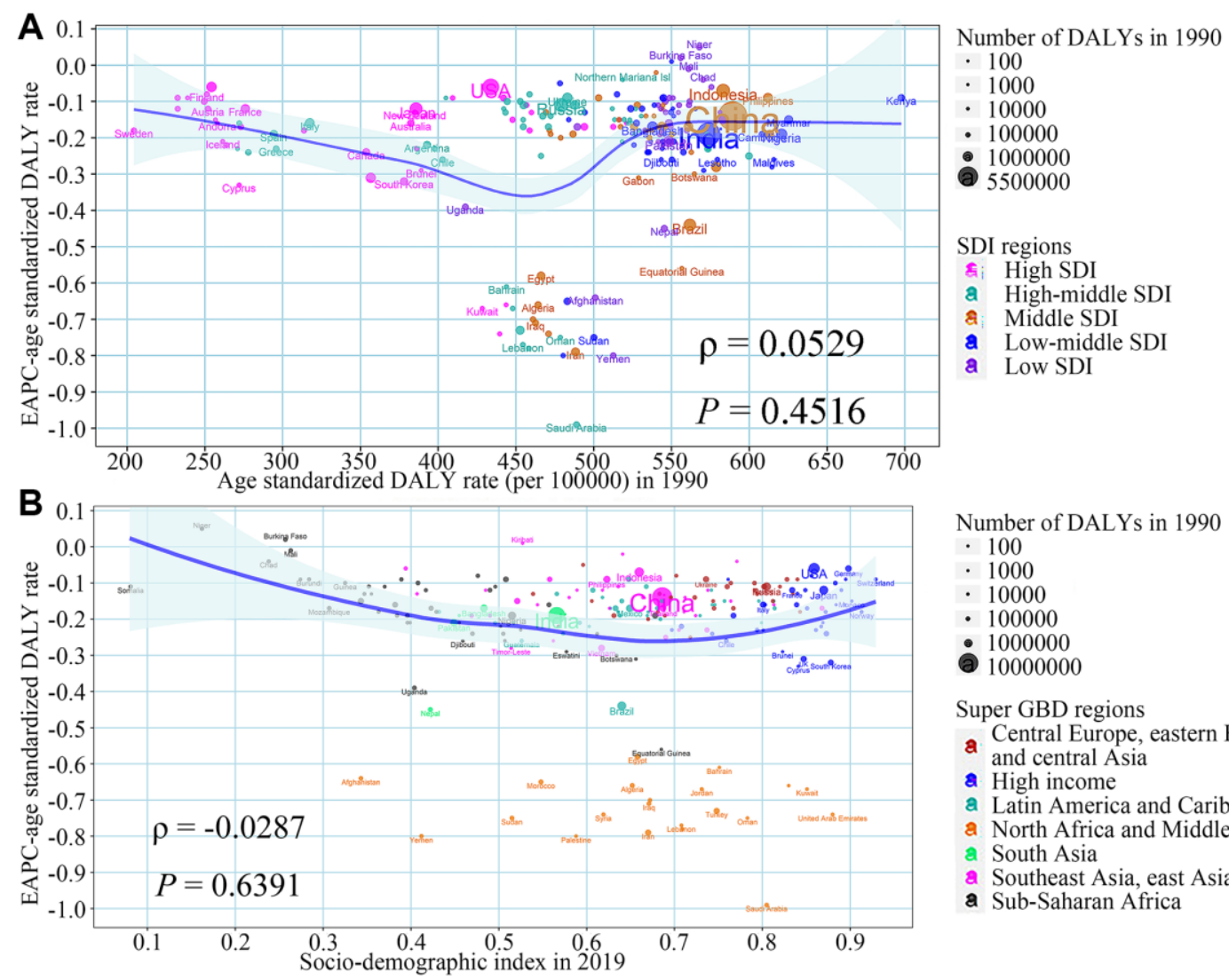

Number of DALYs in 1990

- 100

- 1000

- 10000

- 100000

- 1000000

3. 10000000

Super GBD regions

Central Europe, eastern Europe,

a and central Asia

a High income

a Latin America and Caribbean

a North Africa and Middle East

a South Asia

a Southeast Asia, east Asia, and Oceania

a Sub-Saharan Africa

Figure 3. The association between ASDR in 1990, SDI in 2019, and the EAPC of ASDR from 1990 to 2019. (A) ASDR in 1990 and the EAPC of ASDR from 1990 to 2019; (B) SDI in 2019 and the EAPC of ASDR from 1990 to 2019. The blue line was an adaptive association fitted with adaptive Loess regression based on all data points. Abbreviations: EAPC: estimated annual percentage change; SDI: sociodemographic index; ASDR: age-standardized DALY rate; DALY: disability-adjusted life year. 
ARHL. Previous studies have shown that the disease burden of hearing loss in low SDI countries is heavier than that in high SDI countries, and our research supports this view [5]. Complete occupational noise control regulations, a sufficient number of otolaryngologists, adequate financial support, and accurate disease burden data in high SDI countries can all help these countries reduce the burden of ARHL. In addition, the improvement of the global economy has increased people's purchasing power [7], making some people more willing to spend money on medical services that were unaffordable in the past, such as hearing aids and cochlear implants [8]. This not only improves the hearing level of these people, but also reduces the disease burden of ARHL in these countries where the economy is improving. However, the huge economic impact worldwide brought about by the COVID-19 pandemic and the almost irreversible population aging trend will bring severe challenges to the prevention and control of ARHL. Countries around the world need to work together to take a series of measures to reduce the burden of disease caused by ARHL.

Our study found that mild hearing loss accounted for a large proportion of all ARHL patients, and the ASPR and ASDR of mild ARHL showed an upward trend. The ASPR and ASDR of other severity ARHL showed a downward trend. In recent years, some scholars began to call for hearing screening for the elderly [9]. In 2012, U.S. Preventive Services Task Force published a guideline on hearing screening for people over the age

A

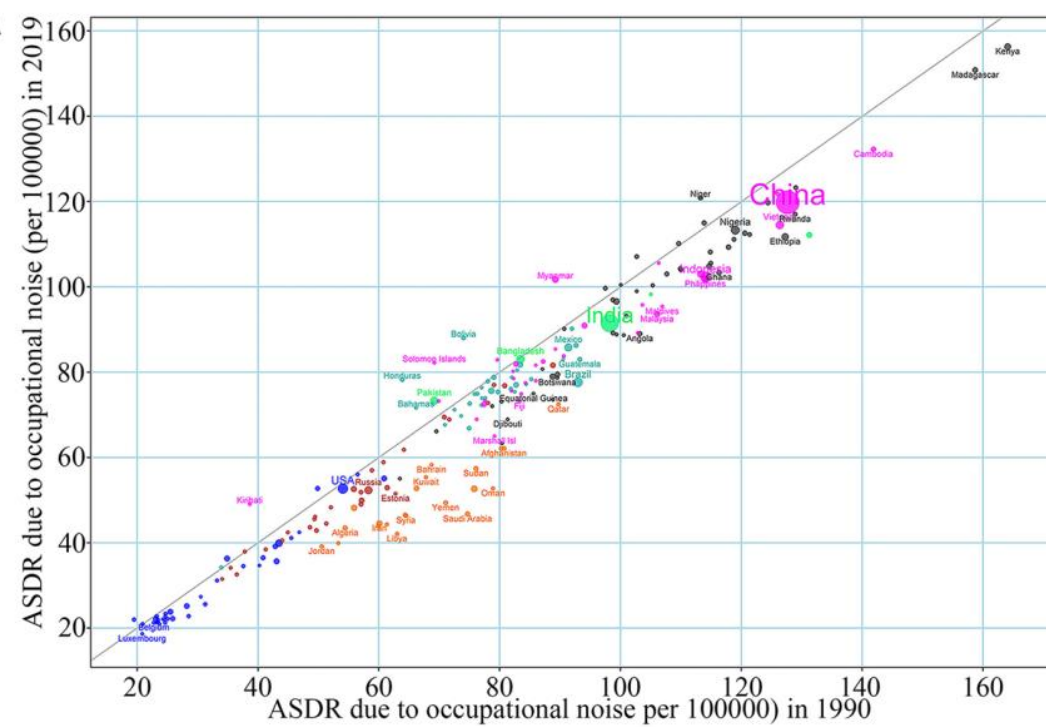

Super GBD regions

a Central Europe, eastern Europe,

and central Asia

a High income

a Latin America and Caribbean

a North Africa and Middle East

a South Asia

a Southeast Asia, east Asia, and Oceania

a Sub-Saharan Africa

B

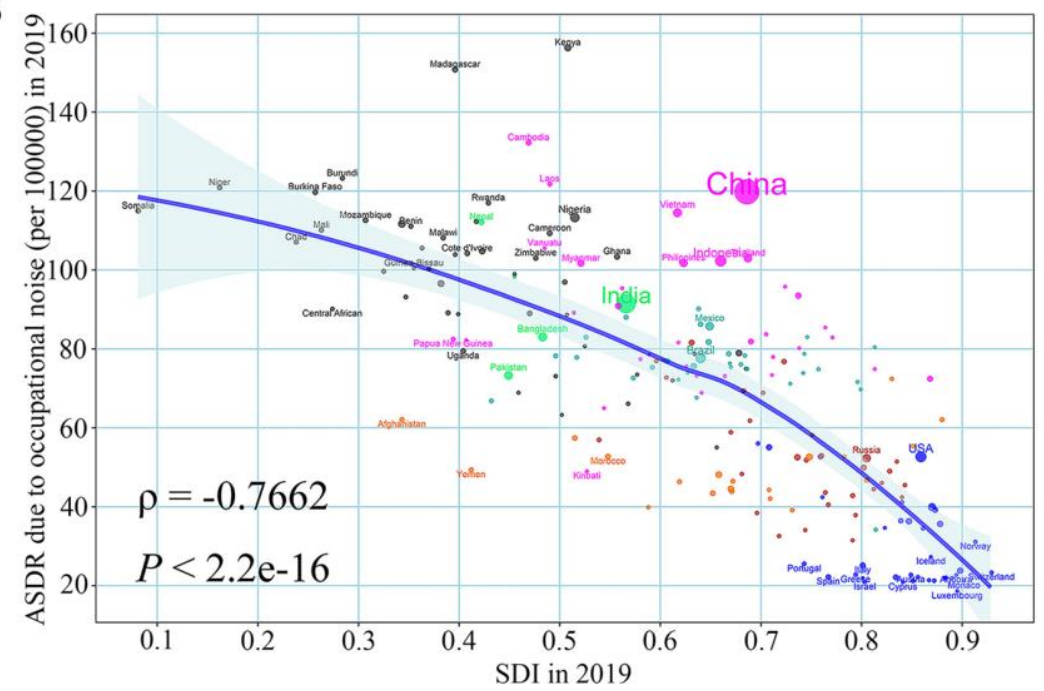

The number in DALYs due

to occupational noise in 2019

- 10

- 100

- 1000

- 10000

- 100000

(3) 1000000

2300000

Figure 4. The relationship between ASDR due to occupational noise in 1990, SDI in 2019 and ASDR due to occupational noise in 2019 in age-related hearing loss. (A) ASDR due to occupational noise in 1990; (B) SDI in 2019. The blue line was an adaptive association fitted with adaptive Loess regression based on all data points. Abbreviations: ASDR: age-standardized DALY rates; SDI: sociodemographic index; DALY: disability-adjusted life year. 
of 50, which detailed the risk assessment, screening test, interventions, and balance of harms and benefits [10]. The progress of hearing screening provided opportunities for the discovery of many patients with mild ARHL. The economic situation will affect people's behavior of seeking help from doctors [11]. The improvement of economic conditions makes people no longer suffer the pain of hearing loss silently as in the past, and seek help from professional doctors, which also increases the chances of discovering the mild hearing loss. In addition, early detection and early treatment of ARHL may prevent a considerable number of people from developing more severe hearing loss, which also increases the number of people with mild hearing loss.

The gratifying result we found is that the ASPR and ASDR of ARHL showed a downward trend in most countries and regions. Noise exposure, especially occupational noise exposure, is one of the important risk factors of ARHL [12]. Since the Second World War in 1945, in order to reduce the impact of occupational noise on hearing loss, humans have adopted measures such as the use of protective equipment, the formulation of regulations and supervision [13]. Obvious downtrends were observed in OSHA occupational noise exposure measurements from 1979 to 2013 [14]. In our study, the burden of ARHL attributable to occupational noise in most countries has shown a downward trend, which also supports the view that noise levels have fallen to a certain extent. Further, some countries, such as Colombia, Brazil, and Chile, have public programs that can provide hearing aids for the elderly, which can further reduce the disease burden of ARHL [8]. In addition, past studies have shown that malnutrition is a potential risk factor for ARHL [15]. The growing economy in some regions may improve the diet of local residents, thereby reducing the incidence of ARHL [16-18]. We also found that countries and territories with higher SDI had a lower disease burden of ARHL attributable to occupational noise. Compared with low SDI countries, high SDI countries have better noise regulations and wider use of protective gear. These may be the reasons for the lower ARHL disease burden attributed to noise in high-SDI countries.

This study has some limitations. First, although GBD collaborators have done a lot of work in assessing the annual burden of disease around the world, they cannot avoid bias in modeling the unavailable data $[19,20]$. Second, due to the limitation of the database, our data may contain a very small amount of hearing loss data caused by other reasons, such as the use of ototoxic drugs or trauma [3,21], which only have little influence on the overall analysis.
In summary, in the past 30 years, ASRs of ARHL in most countries and regions have shown a downward trend, with mild ARHL accounting for most of all ARHL. The ARHL disease burden showed a downward trend with the increase of SDI, and the burden of ARHL due to occupational noise also showed a downward trend. However, as the population ages intensified, the absolute disease burden of ARHL is still heavy. Countries around the world should take effective measures to reduce the ARHL disease burden.

\section{METHODS}

Previous studies have reported the details of the GBD study $[1,19,20]$, and the methods we present here are specific to the ARHL disease burden estimation. Guidelines for Accurate and Transparent Health Estimates Reporting (GATHER) guidelines were followed in every step of analyzing the GBD database [22].

\section{Study data}

In our study, we collected annual prevalent cases, ASPR, DALYs and ASDR of ARHL by 5-year age groups, genders, severity, regions, and risk factors from 1990 to 2019 from the GBD 2019 database via the Global Health Data Exchange (GHDx) query tool (http://ghdx.healthdata.org/gbd-results-tool). Hearing loss was defined as the average intensity of the softest sound that can be heard in one or both ears at a frequency of $0.5,1,2$, and $4 \mathrm{kHz}$ equal to or greater than $20 \mathrm{~dB}$. According to the average intensity, hearing loss can be divided into mild (threshold in 20-34 dB), moderate (threshold in 35-49 dB), moderately severe (threshold in 50-64 dB), severe (threshold in 65-79 dB), profound (threshold in 80-94 dB) and complete (threshold more than $95 \mathrm{~dB}$ ). The data used in this study excluded hearing loss caused by congenital, meningitis, and otitis media. The occupational noise exposure was defined as the proportion of the population occupationally exposed to $85+$ decibels of noise based on population distributions across 17 economic activities, such as agriculture, hunting, forestry, fishing, mining and quarrying. The burden of ARHL for occupational noise was estimated using the population attributable fraction (PAF), which requires information on the relative risk of hearing loss due to occupational noise and occupational noise exposure levels. The relative risks were obtained from published meta-analyses or pooled studies and the formula of PAF was:

$$
P A F=\frac{\sum_{x=1}^{n} R R(x) P(x)-1}{\sum_{x=1}^{n} R R(x) P(x)}
$$

where $P(x)$ is the proportion of population exposed to occupational noise at level $\mathrm{x}$ in the target population 
and $R R(x)$ is the relative risk of occupational noise exposure level $\mathrm{x}[23,24]$. In the GBD database, a total of 204 countries and territories were included and were classified into 5 regions according to their SDIs, which were calculated by combining educational attainment, total fertility rate, and the lag-distributed income per capita. Further, the 204 countries and territories were divided into 21 GBD regions based on geographical proximity and epidemiological similarity, and further simplified into seven Super GBD regions.

Previous studies have introduced the method of disease burden estimation detailly. In short, DisMod MR 2.1 was used to estimate the ARHL disease burden based on published literature and cross-sectional studies. The exposure to risk factors and its attributable burden were quantified by GBD comparative risk assessment $[1,19$, 20]. The age-standardized rates (ASRs) were estimated according to the world population by the GBD study. Relevant data were reported in numbers and $95 \%$ UIs, which were determined by $2.5 \%$ and $97.5 \%$ of the ordered 1000 estimates.

\section{Statistical analysis}

We applied ASPR, ASDR, and EAPC to quantify the trends of ARHL disease burden by age, gender, regions, severity, and risk factors from 1990 to 2019. Standardization is important for this study because it can avoid the difference in age compositions of different groups even of the same population in different periods. The EAPC, a widely used measure that summarized the ASR trends in a specified time interval, was calculated to describe the temporal trends of ASRs of ARHL burden. We put ASR in the regression line model "ln $(\mathrm{ASR})=\alpha+\beta \times$ calendar year $+\varepsilon$ ". The calculation formula of EAPC is $100 \times$ $(\exp (\beta)-1)$. The $95 \% \mathrm{CI}$ for EAPC is also generated from this model. If both the EAPC estimate and the lower boundary of its $95 \% \mathrm{CI}$ are greater than 0 , the ASR is considered to be on the rise. Conversely, if the upper boundary of the EAPC estimate and its 95\% CI is less than 0, then ASR is considered to be a downward trend. Otherwise, ASR is considered stable over time [25-27]. In order to explore the influencing factors of EAPC, we used Spearman rank test to evaluate the relationship between EAPC and ASR (1990) and SDI (2019) respectively at the national level. ASR (1990) reflects the initial disease burden, and SDI (2019) can replace the socioeconomic level and availability of medical services in different countries/territories [25-27]. R program was used in all statistical analyses of our study (version 4.0.3; https://www.R-project.org/), and the $P$-value on both sides of less than 0.05 was considered statistically significant.

\section{Data sharing statement}

To download the data used in these analyses, please visit the Global Health Data Exchange GBD 2019 website:

http://ghdx.healthdata.org/gbd-results-tool.

\section{Ethical statement}

Our study protocol was approved by the Institutional Review Boards of Qilu Hospital of Shandong University with approval number KYLL202011(KS)-239.

\section{Abbreviations}

ARHL: age-related hearing loss; ASRs: agestandardized rates; DALYs: disability-adjusted life years; GBD: The Global Burden of Diseases; UI: uncertainty interval; ASPR: age-standardized prevalence rate; EAPC: estimated annual percentage change; CI: confidence interval; SDI: sociodemographic index.

\section{AUTHOR CONTRIBUTIONS}

X.Yang and M.L. contributed to the conception and design of the work. J.M, H.C, T.Z. and X.Yin contributed to the acquisition, analysis or interpretation of data. J.M. contributed to drafting the article and $\mathrm{X}$.Yang contributed to revising it critically for important intellectual content. All the authors finally approved the version to be published.

\section{ACKNOWLEDGMENTS}

We would like to thank the countless individuals who have contributed to the Global Burden of Disease Study 2019 in various capacities.

\section{CONFLICTS OF INTEREST}

The authors declare no conflicts of interest related to this study.

\section{FUNDING}

This work was supported by the National Natural Science Foundation of China (grant numbers: 82103912, 82173591, and 81973116); the Shandong Provincial Natural Science Foundation (grant number: ZR2020QH302); and the National Key Research and Development Program of China (grant number: 2017YFC0907003). The funders were not involved in the collection, analysis, or interpretation of data, or the writing or submitting of this report. 


\section{REFERENCES}

1. GBD 2019 Hearing Loss Collaborators. Hearing loss prevalence and years lived with disability, 1990-2019: findings from the Global Burden of Disease Study 2019. Lancet. 2021; 397:996-1009.

https://doi.org/10.1016/S0140-6736(21)00516-X PMID:33714390

2. Frisina $\mathrm{RD}$, Ding $\mathrm{B}$, Zhu $\mathrm{X}$, Walton JP. Age-related hearing loss: prevention of threshold declines, cell loss and apoptosis in spiral ganglion neurons. Aging (Albany NY). 2016; 8:2081-99.

https://doi.org/10.18632/aging.101045

PMID:27667674

3. Cunningham LL, Tucci DL. Hearing Loss in Adults. N Engl J Med. 2017; 377:2465-73.

https://doi.org/10.1056/NEJMra1616601 PMID:29262274

4. Masalski M, Morawski K. Worldwide Prevalence of Hearing Loss Among Smartphone Users: CrossSectional Study Using a Mobile-Based App. J Med Internet Res. 2020; 22:e17238.

https://doi.org/10.2196/17238

PMID: $\underline{32706700}$

5. Stevens G, Flaxman S, Brunskill E, Mascarenhas M, Mathers CD, Finucane $M$, and Global Burden of Disease Hearing Loss Expert Group. Global and regional hearing impairment prevalence: an analysis of 42 studies in 29 countries. Eur J Public Health. 2013; 23:146-52.

https://doi.org/10.1093/eurpub/ckr176

PMID:22197756

6. Cheng $X$, Yang Y, Schwebel DC, Liu Z, Li L, Cheng P, Ning $P$, Hu G. Population ageing and mortality during 1990-2017: A global decomposition analysis. PLoS Med. 2020; 17:e1003138.

https://doi.org/10.1371/journal.pmed.1003138 PMID:32511229

7. Ramsey T, Svider PF, Folbe AJ. Health Burden and Socioeconomic Disparities From Hearing Loss: A Global Perspective. Otol Neurotol. 2018; 39:12-6. https://doi.org/10.1097/MA0.0000000000001630 PMID:29210951

8. Fuentes-López E, Fuente A, Valdivia G, LunaMonsalve $M$. Effects of auditory and sociodemographic variables on discontinuation of hearing aid use among older adults with hearing loss fitted in the Chilean public health sector. BMC Geriatr. 2019; 19:245.

https://doi.org/10.1186/s12877-019-1260-6 PMID: 31481016

9. Yueh B, Shapiro N, MacLean CH, Shekelle PG. Screening and management of adult hearing loss in primary care: scientific review. JAMA. 2003; 289:1976-85.

https://doi.org/10.1001/jama.289.15.1976

PMID:12697801

10. Krist $\mathrm{AH}$, Davidson $\mathrm{KW}$, Mangione $\mathrm{CM}$, Cabana $\mathrm{M}$, Caughey $A B$, Davis EM, Donahue KE, Doubeni CA, Epling JW Jr, Kubik M, Li L, Ogedegbe G, Pbert L, et al, and US Preventive Services Task Force. Screening for Hearing Loss in Older Adults: US Preventive Services Task Force Recommendation Statement. JAMA. 2021; 325:1196-201.

https://doi.org/10.1001/jama.2021.2566

PMID:33755083

11. Benova L, Campbell OM, Ploubidis GB. A mediation approach to understanding socio-economic inequalities in maternal health-seeking behaviours in Egypt. BMC Health Serv Res. 2015; 15:1. https://doi.org/10.1186/s12913-014-0652-8 PMID:25603697

12. Sheffield AM, Smith RJH. The Epidemiology of Deafness. Cold Spring Harb Perspect Med. 2019; 9:a033258.

https://doi.org/10.1101/cshperspect.a033258 PMID: 30249598

13. Kerr MJ, Neitzel RL, Hong O, Sataloff RT. Historical review of efforts to reduce noise-induced hearing loss in the United States. Am J Ind Med. 2017; 60:569-77. https://doi.org/10.1002/ajim.22627 PMID:28514024

14. Sayler SK, Roberts BJ, Manning MA, Sun K, Neitzel RL. Patterns and trends in OSHA occupational noise exposure measurements from 1979 to 2013. Occup Environ Med. 2019; 76:118-24.

https://doi.org/10.1136/oemed-2018-105041 PMID:30482879

15. Sardone R, Lampignano L, Guerra V, Zupo R, Donghia R, Castellana F, Battista P, Bortone I, Procino F, Castellana M, Passantino A, Rucco R, Lozupone M, et al. Relationship between Inflammatory Food Consumption and Age-Related Hearing Loss in a Prospective Observational Cohort: Results from the Salus in Apulia Study. Nutrients. 2020; 12:426. https://doi.org/10.3390/nu12020426 PMID: 32046004

16. Gutiérrez-Camacho C, Méndez-Sánchez L, KlünderKlünder M, Clark P, Denova-Gutiérrez E. Association between Sociodemographic Factors and Dietary Patterns in Children Under 24 Months of Age: A Systematic Review. Nutrients. 2019; 11:2006.

https://doi.org/10.3390/nu11092006

PMID:31454895

17. Morseth MS, Grewal NK, Kaasa IS, Hatloy A, Barikmo I, Henjum S. Dietary diversity is related to 
socioeconomic status among adult Saharawi refugees living in Algeria. BMC Public Health. 2017; 17:621. https://doi.org/10.1186/s12889-017-4527-x PMID:28673263

18. Rodrigo L, Campos-Asensio C, Rodríguez MÁ, Crespo I, Olmedillas $\mathrm{H}$. Role of nutrition in the development and prevention of age-related hearing loss: A scoping review. J Formos Med Assoc. 2021; 120:107-20. https://doi.org/10.1016/i.jfma.2020.05.011 PMID: $\underline{32473863}$

19. GBD 2019 Risk Factors Collaborators. Global burden of 87 risk factors in 204 countries and territories, 1990-2019: a systematic analysis for the Global Burden of Disease Study 2019. Lancet. 2020; 396:1223-49.

https://doi.org/10.1016/S0140-6736(20)30752-2 PMID:33069327

20. GBD 2019 Diseases and Injuries Collaborators. Global burden of 369 diseases and injuries in 204 countries and territories, 1990-2019: a systematic analysis for the Global Burden of Disease Study 2019. Lancet. 2020; 396:1204-22.

https://doi.org/10.1016/S0140-6736(20)30925-9 PMID:33069326

21. Lieu JEC, Kenna M, Anne S, Davidson L. Hearing Loss in Children: A Review. JAMA. 2020; 324:2195205.

https://doi.org/10.1001/jama.2020.17647 PMID:33258894

22. Stevens GA, Alkema L, Black RE, Boerma JT, Collins GS, Ezzati M, Grove JT, Hogan DR, Hogan MC, Horton $R$, Lawn JE, Marušić A, Mathers $C D$, et al, and (The GATHER Working Group). Guidelines for Accurate and Transparent Health Estimates Reporting: the GATHER statement. Lancet. 2016; 388:e19-23. https://doi.org/10.1016/S0140-6736(16)30388-9 PMID:27371184
23. GBD 2016 Occupational Risk Factors Collaborators. Global and regional burden of disease and injury in 2016 arising from occupational exposures: a systematic analysis for the Global Burden of Disease Study 2016. Occup Environ Med. 2020; 77:133-41.

https://doi.org/10.1136/oemed-2019-106008 PMID: 32054817

24. Li N, Zhai Z, Zheng $Y$, Lin S, Deng $Y$, Xiang G, Yao J, Xiang D, Wang S, Yang P, Yang S, Xu P, Wu Y, et al. Association of 13 Occupational Carcinogens in Patients With Cancer, Individually and Collectively, 1990-2017. JAMA Netw Open. 2021; 4:e2037530.

https://doi.org/10.1001/jamanetworkopen.2020.37530 PMID:33599775

25. Yang X, Man J, Chen H, Zhang T, Yin X, He Q, Lu M. Temporal trends of the lung cancer mortality attributable to smoking from 1990 to 2017: A global, regional and national analysis. Lung Cancer. 2021; 152:49-57.

https://doi.org/10.1016/i.lungcan.2020.12.007 PMID:33348250

26. Liu Z, Jiang $Y$, Yuan H, Fang $Q$, Cai N, Suo C, Jin L, Zhang $\mathrm{T}$, Chen $\mathrm{X}$. The trends in incidence of primary liver cancer caused by specific etiologies: Results from the Global Burden of Disease Study 2016 and implications for liver cancer prevention. J Hepatol. 2019; 70:674-83.

https://doi.org/10.1016/j.jhep.2018.12.001 PMID:30543829

27. Yang X, Chen H, Zhang T, Yin X, Man J, He Q, Lu M. Global, regional, and national burden of blindness and vision loss due to common eye diseases along with its attributable risk factors from 1990 to 2019: a systematic analysis from the global burden of disease study 2019. Aging (Albany NY). 2021; 13:19614-42. https://doi.org/10.18632/aging.203374 PMID: $\underline{34371482}$ 


\section{SUPPLEMENTARY MATERIALS}

\section{Supplementary Figures}

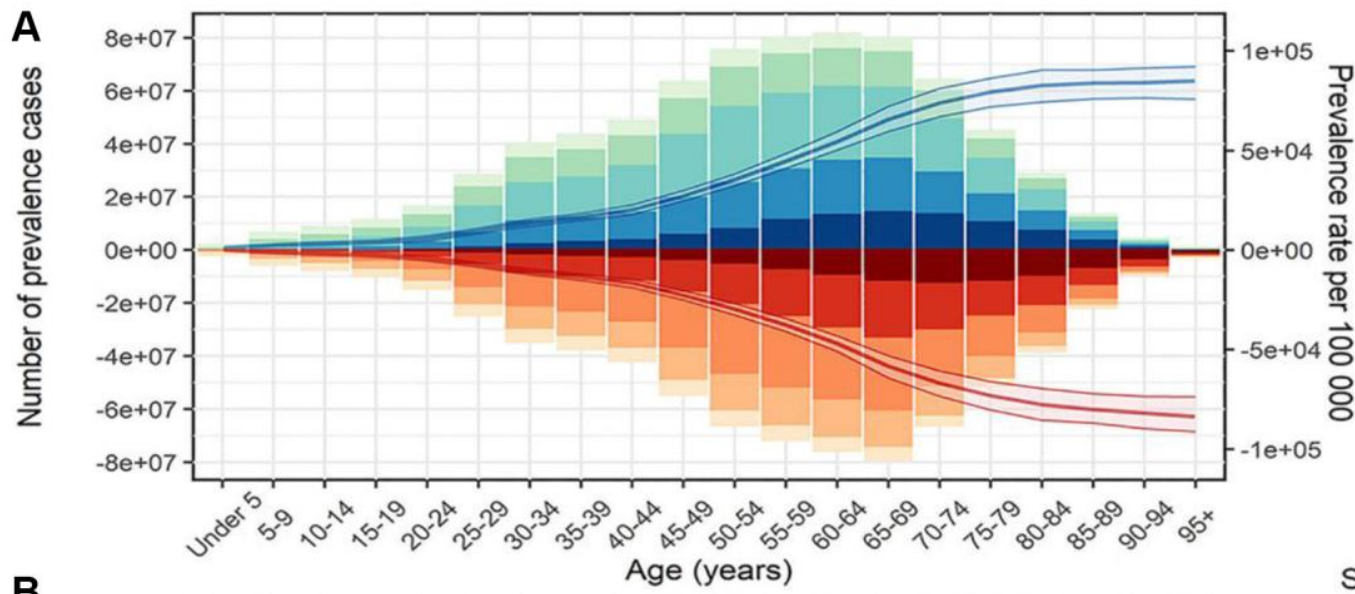

B

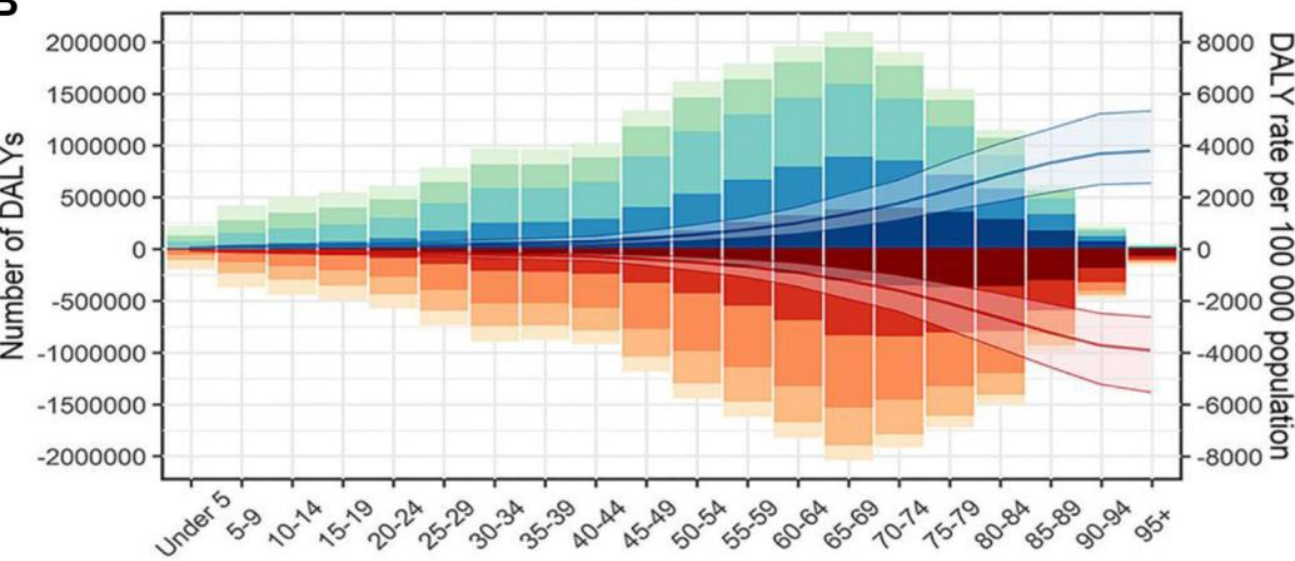

Sex (rate)

Male/Global

Female/Global

Sex/SDI region (number)

Male/High SDI

Male/High-middle SDI

Male/Middle SDI

Male/Low-middle SDI

Male/Low SDI

Female/High SDI

Female/High-middle SDI

Female/Middle SD

Female/Low-middle SDI

Female/Low SDI

Supplementary Figure 1. Prevalent cases, DALYs and the corresponding rates of ARHL by sex, age group, and SDI regions in 2019. (A) Prevalent cases and prevalence rate; (B) DALYs and DALY rate. Abbreviations: SDI: socio-demographic index; ARHL: age-related hearing loss; DALY: disability adjusted life year. 

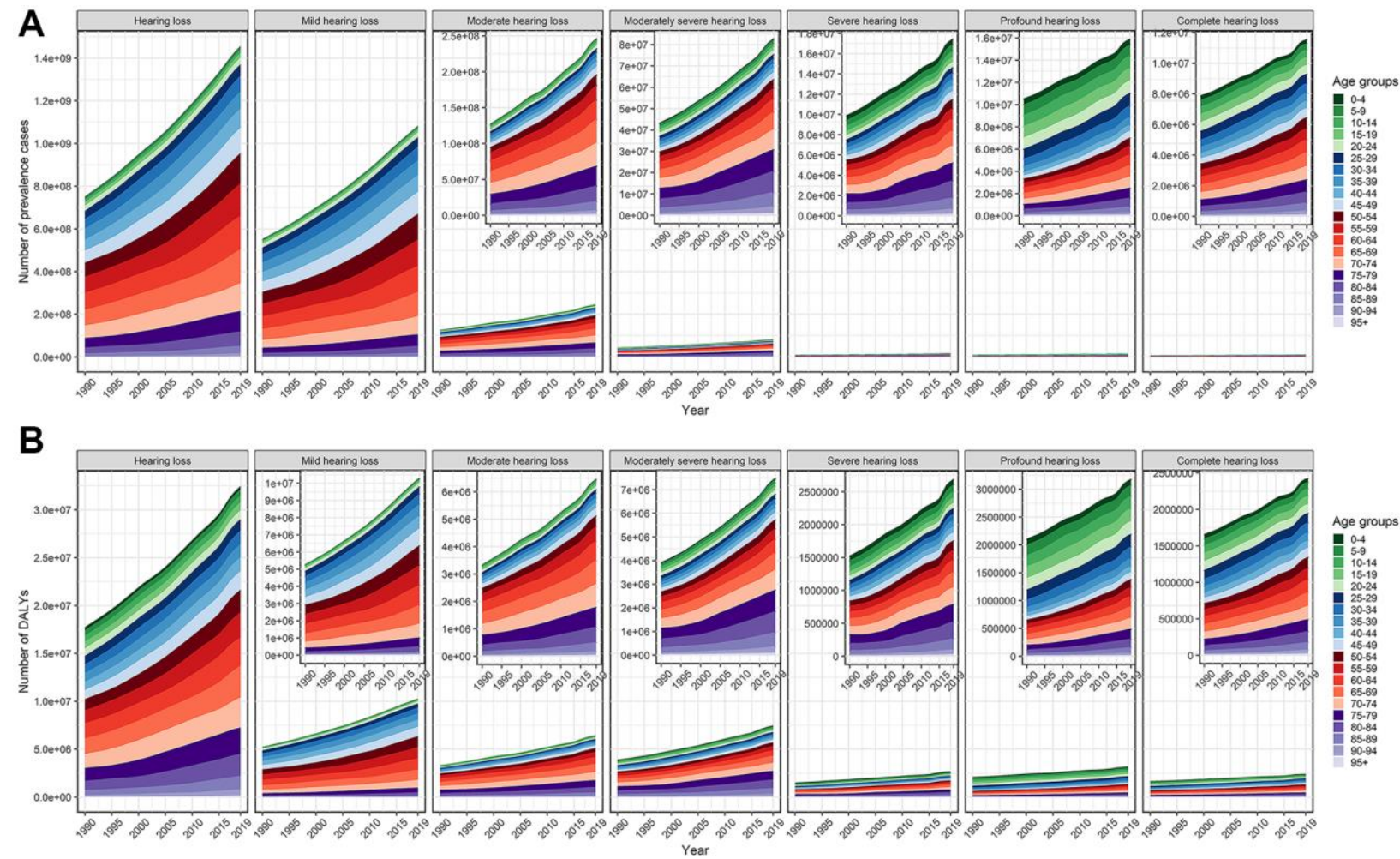

Supplementary Figure 2. The prevalent cases and DALYs of ARHL by severity and age groups from 1990 to 2019. (A) Prevalent cases; (B) DALYs. Abbreviations: ARHL: age-related hearing loss; DALY: disability adjusted life year.
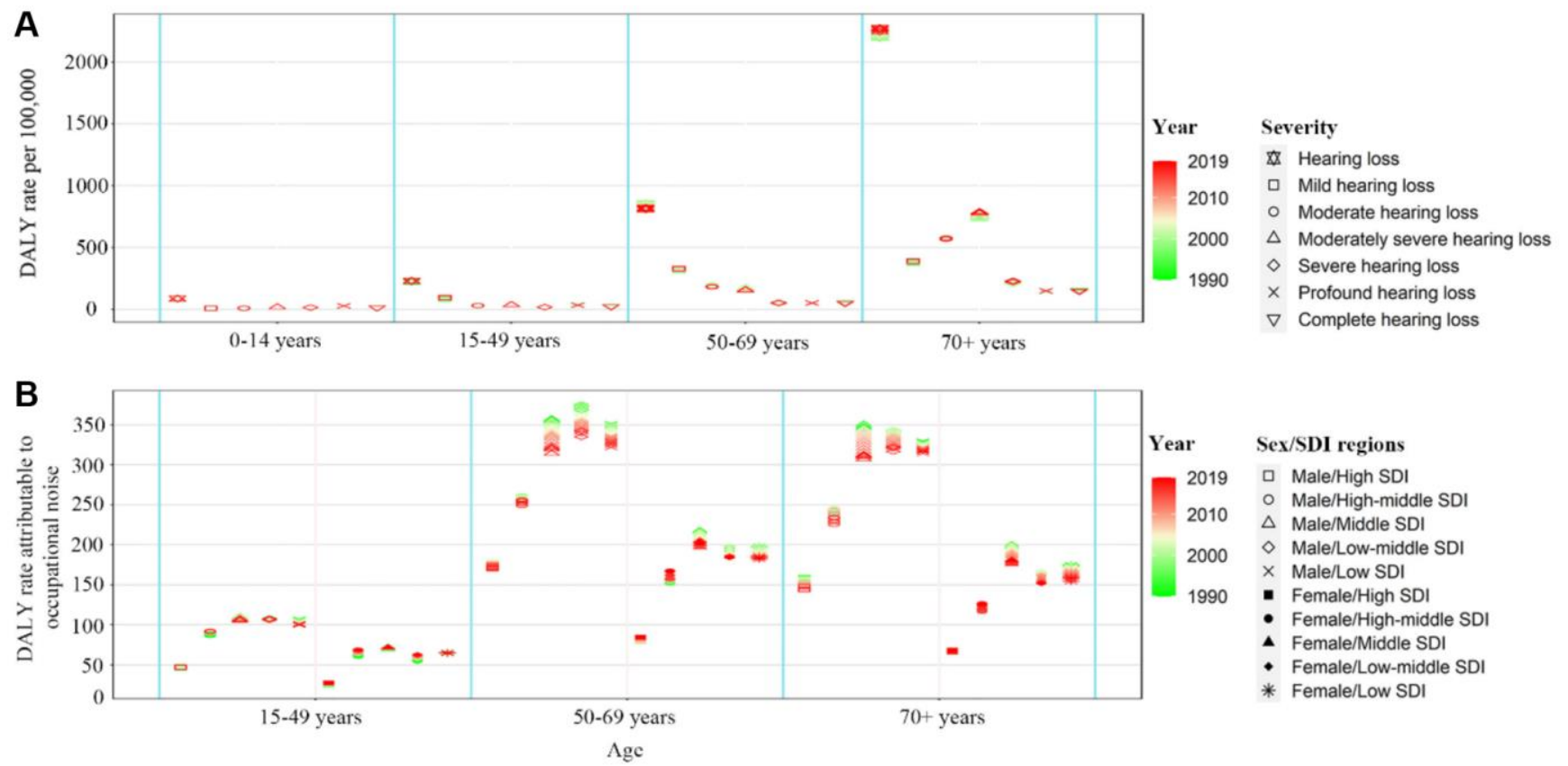

Supplementary Figure 3. The trends of DALY rate and DALY rate attributable to occupational noise by sex, age groups, severity, and SDI regions from 1990 to 2019. (A) DALY rate by age groups and severity; (B) DALY rate attributable to occupational noise by sex, age groups and SDI regions. Abbreviations: SDI: socio-demographic index; DALY: disability adjusted life year. 


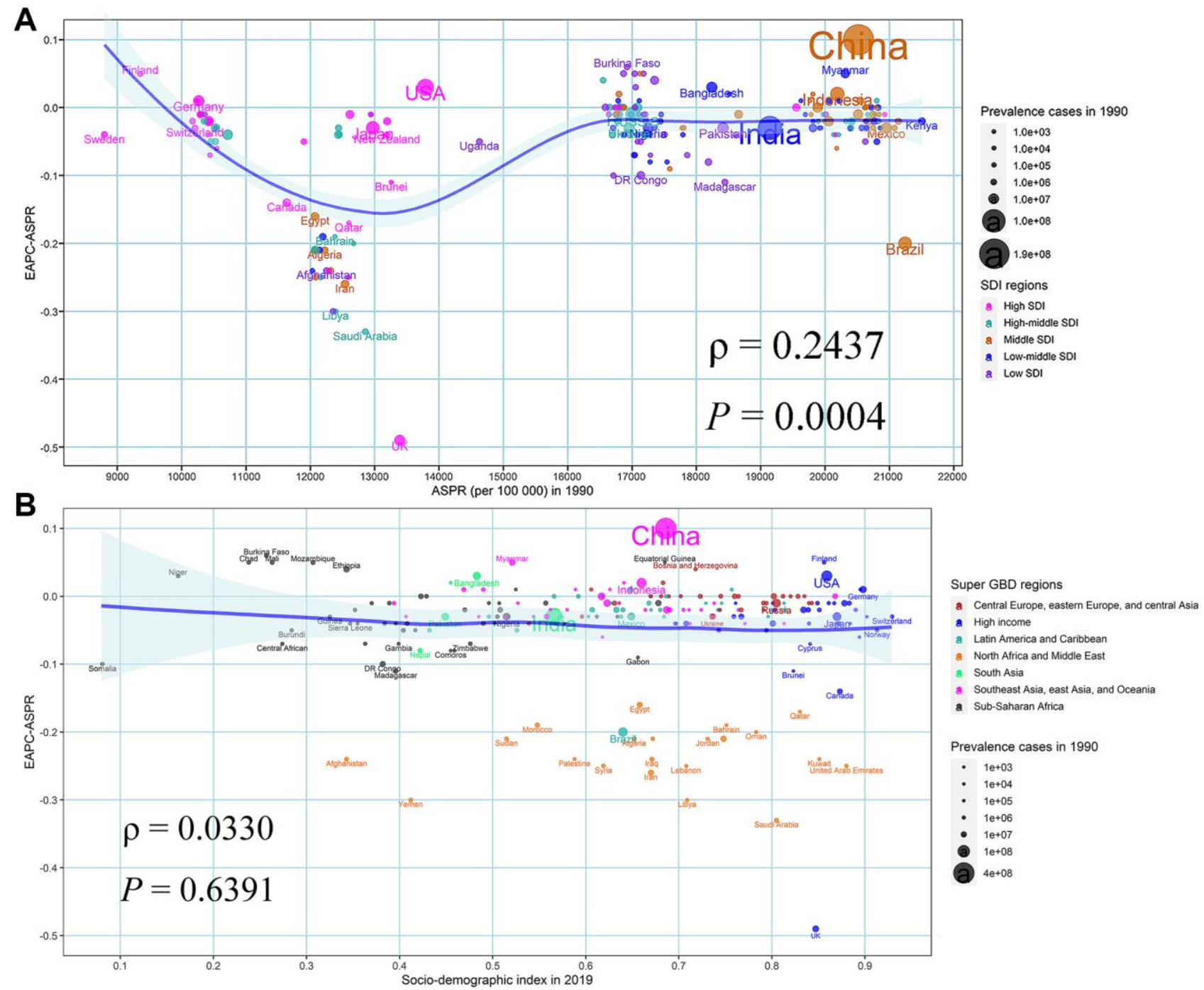

Supplementary Figure 4. The association between ASPR in 1990, SDI in 2019, and the EAPC of ASPR from 1990 to 2019. (A) ASPR in 1990 and the EAPC of ASPR from 1990 to 2019; (B) SDI in 2019 and the EAPC of ASPR from 1990 to 2019. The blue line was an adaptive association fitted with adaptive Loess regression based on all data points. Abbreviations: EAPC: estimated annual percentage change; ASPR: age-standardized prevalence rate; SDI: socio-demographic index. 

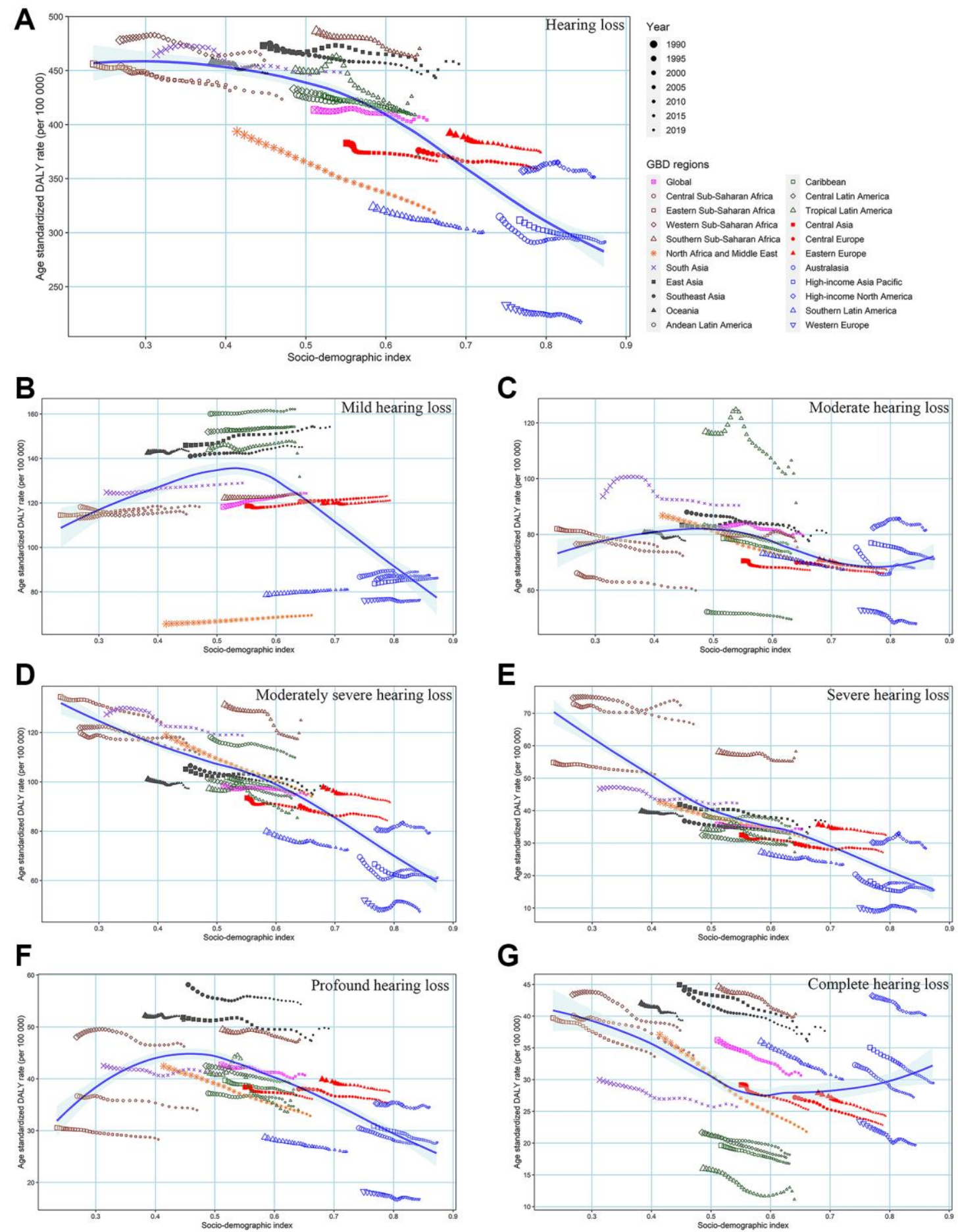

Supplementary Figure 5. The association between ASDR and SDI by GBD regions and severity from 1990 to 2019. (A) total ARHL; (B) mild ARHL; (C) moderate ARHL; (D) moderately severe ARHL; (E) severe ARHL; (F) profound ARHL; (G) complete ARHL. The blue line was an adaptive association fitted with adaptive Loess regression based on all data points. Abbreviations: ASDR: age-standardized DALY rates; SDI: socio-demographic index; DALY: disability adjusted life year; ARHL: age-related hearing loss; GBD: global burden of disease. 

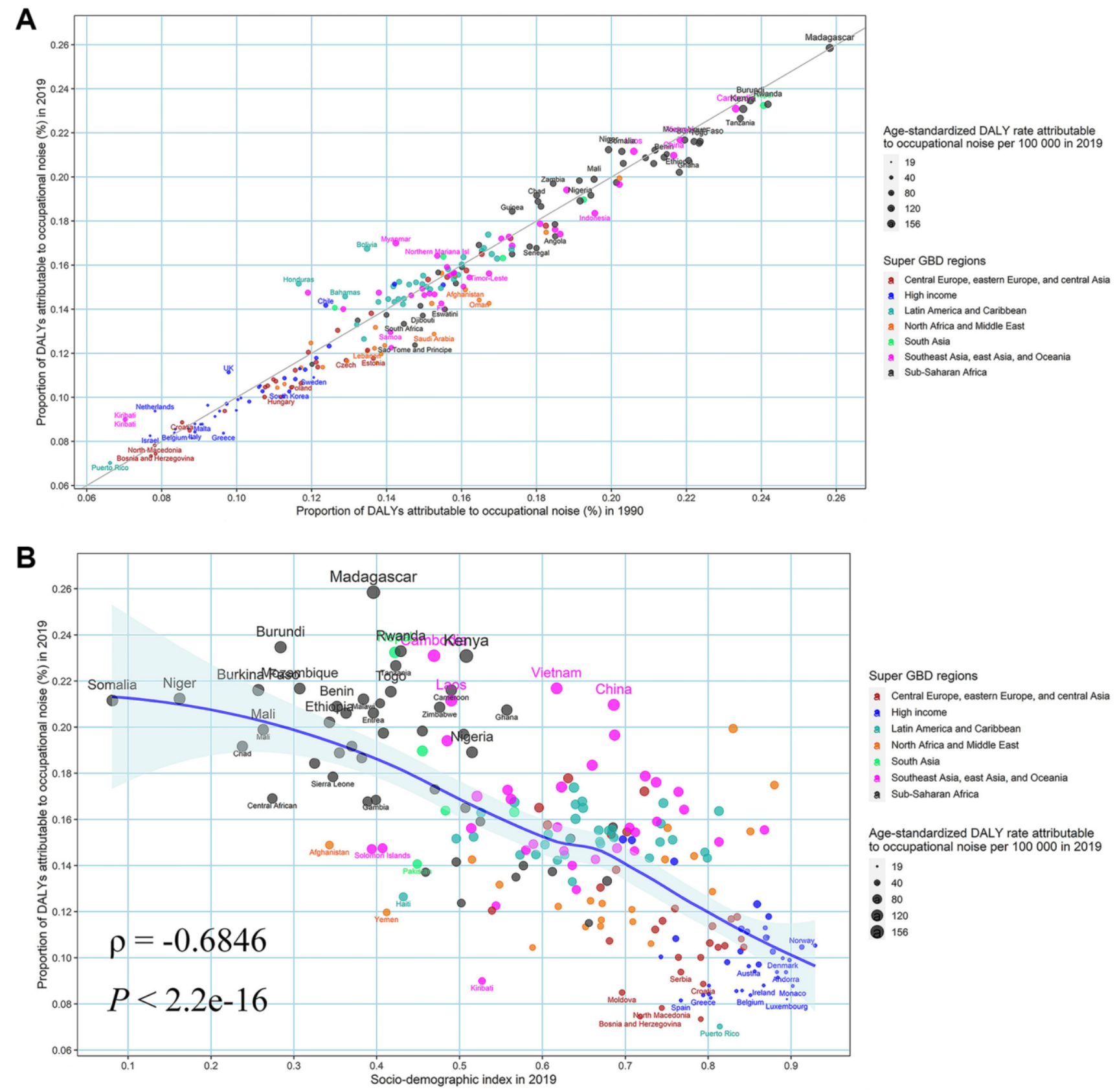

Supplementary Figure 6. The relationship between proportion of DALYs attributable to occupational noise in 1990, SDI in 2019 and proportion of DALYs attributable to occupational noise in 2019 in ARHL. (A) Proportion of DALYs attributable to occupational noise in 1990; (B) SDI in 2019. The blue line was an adaptive association fitted with adaptive Loess regression based on all data points. Abbreviations: DALY: disability adjusted life year; SDI: socio-demographic index; ARHL: age-related hearing loss. 


\section{Supplementary Tables}

Please browse Full Text version to see the data of Supplementary Table 1.

\section{Supplementary Table 1. Age-related hearing loss prevalent cases and burden in 1990 and 2019 and the temporal trends from 1990 to 2019 in 204 countries.}

\section{Supplementary Table 2. Age-related hearing loss prevalent cases and burden in 1990 and 2019 and the temporal trends from 1990 to 2019 in GBD regions.}

\begin{tabular}{|c|c|c|c|c|c|c|c|c|c|c|}
\hline \multirow{4}{*}{ Characteristics } & \multicolumn{4}{|c|}{1990} & \multicolumn{4}{|c|}{2019} & \multicolumn{2}{|c|}{ EAPC (1990-2019) } \\
\hline & \multicolumn{2}{|c|}{ Prevalent cases } & \multicolumn{2}{|c|}{ DALYs } & \multicolumn{2}{|c|}{ Prevalent cases } & \multicolumn{2}{|c|}{ DALYs } & \multirow[t]{2}{*}{ ASPR } & \multirow[t]{2}{*}{ ASDR } \\
\hline & & ASPR & & ASDR & & ASPR & & ASDR & & \\
\hline & $\begin{array}{l}\text { No. } \times 10^{6} \\
(95 \% \text { UI) }\end{array}$ & $\begin{array}{l}\begin{array}{l}\text { No. } \times 10^{-2} \\
(95 \% \text { UI) }\end{array} \\
\end{array}$ & $\begin{array}{l}\text { No. } \times 10^{6} \\
(95 \% \text { UI) }\end{array}$ & $\begin{array}{l}\text { No. } \times 10^{-3} \\
(95 \% \text { UI) }\end{array}$ & $\begin{array}{l}\text { No. } \times 10^{6} \\
(95 \% \text { UI) }\end{array}$ & $\begin{array}{l}\begin{array}{l}\text { No. } \times 10^{-2} \\
(95 \% \text { UI) }\end{array} \\
\end{array}$ & $\begin{array}{l}\text { No. } \times 10^{6} \\
(95 \% \text { UI) }\end{array}$ & $\begin{array}{l}\text { No. } \times 10^{-3} \\
(95 \% \text { UI })\end{array}$ & $\begin{array}{c}\text { No. } \\
(95 \% \text { CI }) \\
\end{array}$ & $\begin{array}{c}\text { No. } \\
(95 \% \text { CI }) \\
\end{array}$ \\
\hline \multicolumn{11}{|l|}{ GBD region } \\
\hline $\begin{array}{l}\text { High-income } \\
\text { Asia Pacific }\end{array}$ & $\begin{array}{c}25.70 \\
(24.43,27.01)\end{array}$ & $\begin{array}{c}12.90 \\
(12.28,13.55)\end{array}$ & $\begin{array}{c}0.75 \\
(0.50,1.07)\end{array}$ & $\begin{array}{c}3.84 \\
(2.60,5.46)\end{array}$ & $\begin{array}{c}46.92 \\
(44.34,49.52)\end{array}$ & $\begin{array}{c}12.81 \\
(12.18,13.45)\end{array}$ & $\begin{array}{c}1.42 \\
(0.97,2.01)\end{array}$ & $\begin{array}{c}3.62 \\
(2.46,5.19)\end{array}$ & $\begin{array}{c}-0.03 \\
(-0.03,-0.02)\end{array}$ & $\begin{array}{c}-0.17 \\
(-0.19,-0.15)\end{array}$ \\
\hline $\begin{array}{l}\text { High-income } \\
\text { North America }\end{array}$ & $\begin{array}{c}45.79 \\
(43.22,48.49)\end{array}$ & $\begin{array}{c}13.58 \\
(12.85,14.35)\end{array}$ & $\begin{array}{c}1.45 \\
(1.01,2.02)\end{array}$ & $\begin{array}{c}4.26 \\
(2.94,5.96)\end{array}$ & $\begin{array}{c}77.49 \\
(73.00,82.00)\end{array}$ & $\begin{array}{c}13.71 \\
(12.96,14.48)\end{array}$ & $\begin{array}{c}2.39 \\
(1.67,3.34)\end{array}$ & $\begin{array}{c}4.18 \\
(2.88,5.85)\end{array}$ & $\begin{array}{c}0.00 \\
(-0.02,0.03)\end{array}$ & $\begin{array}{c}-0.08 \\
(-0.13,-0.04)\end{array}$ \\
\hline $\begin{array}{l}\text { Western } \\
\text { Europe }\end{array}$ & $\begin{array}{c}57.52 \\
(54.41,60.78)\end{array}$ & $\begin{array}{c}10.85 \\
(10.30,11.40)\end{array}$ & $\begin{array}{c}1.54 \\
(1.04,2.23)\end{array}$ & $\begin{array}{c}2.87 \\
(1.95,4.17)\end{array}$ & $\begin{array}{c}79.97 \\
(75.45,84.83)\end{array}$ & $\begin{array}{c}10.59 \\
(10.04,11.15)\end{array}$ & $\begin{array}{c}2.16 \\
(1.45,3.12)\end{array}$ & $\begin{array}{c}2.69 \\
(1.81,3.92)\end{array}$ & $\begin{array}{c}-0.10 \\
(-0.11,-0.09)\end{array}$ & $\begin{array}{c}-0.16 \\
(-0.18,-0.13)\end{array}$ \\
\hline Australasia & $\begin{array}{c}3.03 \\
(2.92,3.13)\end{array}$ & $\begin{array}{c}13.19 \\
(12.71,13.64)\end{array}$ & $\begin{array}{c}0.09 \\
(0.06,0.12)\end{array}$ & $\begin{array}{c}3.83 \\
(2.65,5.43)\end{array}$ & $\begin{array}{c}5.74 \\
(5.40,6.09)\end{array}$ & $\begin{array}{c}13.01 \\
(12.33,13.77)\end{array}$ & $\begin{array}{c}0.16 \\
(0.11,0.23)\end{array}$ & $\begin{array}{c}3.57 \\
(2.41,5.10)\end{array}$ & $\begin{array}{c}-0.03 \\
(-0.05,0.00)\end{array}$ & $\begin{array}{c}-0.15 \\
(-0.22,-0.09)\end{array}$ \\
\hline $\begin{array}{l}\text { Andean Latin } \\
\text { America }\end{array}$ & $\begin{array}{c}23.12 \\
(21.95,24.37)\end{array}$ & $\begin{array}{c}21.24 \\
(20.21,22.34)\end{array}$ & $\begin{array}{c}0.59 \\
(0.40,0.87)\end{array}$ & $\begin{array}{c}5.61 \\
(3.75,8.11)\end{array}$ & $\begin{array}{c}45.73 \\
(43.90,47.67)\end{array}$ & $\begin{array}{c}18.58 \\
(17.83,19.35)\end{array}$ & $\begin{array}{c}1.13 \\
(0.74,1.63)\end{array}$ & $\begin{array}{c}4.67 \\
(3.08,6.74)\end{array}$ & $\begin{array}{c}-0.20 \\
(-0.29,-0.11)\end{array}$ & $\begin{array}{c}-0.43 \\
(-0.55,-0.32)\end{array}$ \\
\hline $\begin{array}{l}\text { Tropical Latin } \\
\text { America }\end{array}$ & $\begin{array}{c}5.05 \\
(4.76,5.35)\end{array}$ & $\begin{array}{c}20.73 \\
(19.52,22.00)\end{array}$ & $\begin{array}{c}0.13 \\
(0.09,0.19)\end{array}$ & $\begin{array}{c}5.30 \\
(3.56,7.65)\end{array}$ & $\begin{array}{c}12.17 \\
(11.48,12.90)\end{array}$ & $\begin{array}{c}20.66 \\
(19.48,21.92)\end{array}$ & $\begin{array}{c}0.29 \\
(0.20,0.43)\end{array}$ & $\begin{array}{c}5.08 \\
(3.41,7.38)\end{array}$ & $\begin{array}{c}0.00 \\
(-0.01,0.01)\end{array}$ & $\begin{array}{c}-0.11 \\
(-0.13,-0.09)\end{array}$ \\
\hline $\begin{array}{l}\text { Central Latin } \\
\text { America }\end{array}$ & $\begin{array}{c}21.32 \\
(20.16,22.53)\end{array}$ & $\begin{array}{c}20.83 \\
(19.76,22.00)\end{array}$ & $\begin{array}{c}0.54 \\
(0.36,0.79)\end{array}$ & $\begin{array}{c}5.37 \\
(3.61,7.69)\end{array}$ & $\begin{array}{c}50.72 \\
(48.03,53.58)\end{array}$ & $\begin{array}{c}20.65 \\
(19.56,21.82)\end{array}$ & $\begin{array}{c}1.23 \\
(0.82,1.80)\end{array}$ & $\begin{array}{c}5.11 \\
(3.42,7.41)\end{array}$ & $\begin{array}{c}-0.03 \\
(-0.03,-0.03)\end{array}$ & $\begin{array}{c}-0.17 \\
(-0.18,-0.16)\end{array}$ \\
\hline $\begin{array}{l}\text { Southern Latin } \\
\text { America }\end{array}$ & $\begin{array}{c}5.77 \\
(5.47,6.10)\end{array}$ & $\begin{array}{c}12.44 \\
(11.80,13.12)\end{array}$ & $\begin{array}{c}0.18 \\
(0.13,0.26)\end{array}$ & $\begin{array}{c}3.95 \\
(2.73,5.59)\end{array}$ & $\begin{array}{c}9.84 \\
(9.32,10.38)\end{array}$ & $\begin{array}{c}12.30 \\
(11.66,12.94)\end{array}$ & $\begin{array}{c}0.30 \\
(0.20,0.42)\end{array}$ & $\begin{array}{c}3.67 \\
(2.52,5.21)\end{array}$ & $\begin{array}{c}-0.04 \\
(-0.04,-0.03)\end{array}$ & $\begin{array}{c}-0.23 \\
(-0.24,-0.22)\end{array}$ \\
\hline Caribbean & $\begin{array}{c}5.83 \\
(5.52,6.16)\end{array}$ & $\begin{array}{c}20.74 \\
(19.64,21.93)\end{array}$ & $\begin{array}{c}0.15 \\
(0.10,0.22)\end{array}$ & $\begin{array}{c}5.35 \\
(3.57,7.72)\end{array}$ & $\begin{array}{c}10.52 \\
(9.93,11.11)\end{array}$ & $\begin{array}{c}20.56 \\
(19.42,21.72)\end{array}$ & $\begin{array}{c}0.26 \\
(0.17,0.37)\end{array}$ & $\begin{array}{c}5.10 \\
(3.40,7.33)\end{array}$ & $\begin{array}{c}-0.02 \\
(-0.03,-0.02)\end{array}$ & $\begin{array}{c}-0.15 \\
(-0.16,-0.15)\end{array}$ \\
\hline Eastern Europe & $\begin{array}{c}45.30 \\
(43.28,47.37)\end{array}$ & $\begin{array}{c}16.97 \\
(16.24,17.75)\end{array}$ & $\begin{array}{c}1.24 \\
(0.84,1.76)\end{array}$ & $\begin{array}{c}4.79 \\
(3.25,6.82)\end{array}$ & $\begin{array}{c}51.89 \\
(49.58,54.25)\end{array}$ & $\begin{array}{c}16.84 \\
(16.12,17.61)\end{array}$ & $\begin{array}{c}1.40 \\
(0.95,2.00)\end{array}$ & $\begin{array}{c}4.60 \\
(3.13,6.54)\end{array}$ & $\begin{array}{c}-0.02 \\
(-0.03,-0.01)\end{array}$ & $\begin{array}{c}-0.11 \\
(-0.12,-0.10)\end{array}$ \\
\hline Central Europe & $\begin{array}{c}23.90 \\
(22.84,25.01)\end{array}$ & $\begin{array}{c}16.87 \\
(16.15,17.65)\end{array}$ & $\begin{array}{c}0.64 \\
(0.43,0.91)\end{array}$ & $\begin{array}{c}4.62 \\
(3.11,6.57)\end{array}$ & $\begin{array}{c}30.42 \\
(29.04,31.95)\end{array}$ & $\begin{array}{c}16.85 \\
(16.12,17.61)\end{array}$ & $\begin{array}{c}0.81 \\
(0.55,1.16)\end{array}$ & $\begin{array}{c}4.43 \\
(3.00,6.35)\end{array}$ & $\begin{array}{c}0.00 \\
(0.00,0.01)\end{array}$ & $\begin{array}{c}-0.11 \\
(-0.13,-0.10)\end{array}$ \\
\hline Central Asia & $\begin{array}{c}8.67 \\
(8.25,9.09)\end{array}$ & $\begin{array}{c}16.79 \\
(16.04,17.58)\end{array}$ & $\begin{array}{c}0.25 \\
(0.17,0.35)\end{array}$ & $\begin{array}{c}4.75 \\
(3.21,6.77)\end{array}$ & $\begin{array}{c}13.74 \\
(13.10,14.40)\end{array}$ & $\begin{array}{c}16.71 \\
(15.98,17.47)\end{array}$ & $\begin{array}{c}0.35 \\
(0.24,0.51)\end{array}$ & $\begin{array}{c}4.55 \\
(3.07,6.47)\end{array}$ & $\begin{array}{c}-0.01 \\
(-0.02,0.01)\end{array}$ & $\begin{array}{c}-0.14 \\
(-0.15,-0.13)\end{array}$ \\
\hline $\begin{array}{l}\text { North Africa } \\
\text { and Middle East }\end{array}$ & $\begin{array}{c}24.09 \\
(22.55,25.59)\end{array}$ & $\begin{array}{c}12.25 \\
(11.57,12.91)\end{array}$ & $\begin{array}{c}0.95 \\
(0.66,1.31)\end{array}$ & $\begin{array}{c}4.73 \\
(3.38,6.55)\end{array}$ & $\begin{array}{c}54.84 \\
(51.73,57.98)\end{array}$ & $\begin{array}{c}11.47 \\
(10.86,12.12)\end{array}$ & $\begin{array}{c}1.76 \\
(1.21,2.48)\end{array}$ & $\begin{array}{c}3.84 \\
(2.69,5.36)\end{array}$ & $\begin{array}{c}-0.22 \\
(-0.23,-0.21)\end{array}$ & $\begin{array}{c}-0.72 \\
(-0.74,-0.71)\end{array}$ \\
\hline South Asia & $\begin{array}{c}133.59 \\
(126.21,141.38)\end{array}$ & $\begin{array}{c}18.97 \\
(18.14,19.86)\end{array}$ & $\begin{array}{c}4.05 \\
(2.72,5.74)\end{array}$ & $\begin{array}{c}5.69 \\
(3.90,8.04)\end{array}$ & $\begin{array}{c}297.91 \\
(284.41,311.83)\end{array}$ & $\begin{array}{c}19.08 \\
(18.30,19.92)\end{array}$ & $\begin{array}{c}8.44 \\
(5.74,12.04)\end{array}$ & $\begin{array}{c}5.50 \\
(3.79,7.79)\end{array}$ & $\begin{array}{c}-0.02 \\
(-0.04,-0.01)\end{array}$ & $\begin{array}{c}-0.21 \\
(-0.25,-0.17)\end{array}$ \\
\hline Southeast Asia & $\begin{array}{c}65.68 \\
(62.55,68.83)\end{array}$ & $\begin{array}{c}20.19 \\
(19.42,20.97)\end{array}$ & $\begin{array}{c}1.95 \\
(1.30,2.78)\end{array}$ & $\begin{array}{c}5.88 \\
(4.03,8.36)\end{array}$ & $\begin{array}{c}134.00 \\
(128.85,139.12)\end{array}$ & $\begin{array}{c}20.12 \\
(19.39,20.87)\end{array}$ & $\begin{array}{c}3.55 \\
(2.38,5.11)\end{array}$ & $\begin{array}{c}5.56 \\
(3.77,7.91)\end{array}$ & $\begin{array}{c}0.01 \\
(-0.01,0.02)\end{array}$ & $\begin{array}{c}-0.14 \\
(-0.15,-0.12)\end{array}$ \\
\hline East Asia & $\begin{array}{c}206.40 \\
(196.71,215.86)\end{array}$ & $\begin{array}{c}20.49 \\
(19.58,21.37)\end{array}$ & $\begin{array}{c}5.76 \\
(3.87,8.24)\end{array}$ & $\begin{array}{c}5.87 \\
(4.02,8.36)\end{array}$ & $\begin{array}{c}420.07 \\
(402.28,438.67)\end{array}$ & $\begin{array}{c}21.05 \\
(20.19,21.94)\end{array}$ & $\begin{array}{c}10.80 \\
(7.24,15.54)\end{array}$ & $\begin{array}{c}5.69 \\
(3.88,8.11)\end{array}$ & $\begin{array}{c}0.10 \\
(0.07,0.12)^{*}\end{array}$ & $\begin{array}{c}-0.14 \\
(-0.19,-0.10)\end{array}$ \\
\hline Oceania & $\begin{array}{c}0.81 \\
(0.77,0.85)\end{array}$ & $\begin{array}{c}19.98 \\
(19.23,20.74)\end{array}$ & $\begin{array}{c}0.02 \\
(0.02,0.03)\end{array}$ & $\begin{array}{c}5.66 \\
(3.83,8.04)\end{array}$ & $\begin{array}{c}1.86 \\
(1.77,1.95)\end{array}$ & $\begin{array}{c}19.86 \\
(19.11,20.63)\end{array}$ & $\begin{array}{c}0.05 \\
(0.03,0.07)\end{array}$ & $\begin{array}{c}5.51 \\
(3.76,7.81)\end{array}$ & $\begin{array}{c}-0.01 \\
(-0.03,0.00)\end{array}$ & $\begin{array}{c}-0.06 \\
(-0.08,-0.05)\end{array}$ \\
\hline $\begin{array}{l}\text { Western } \\
\text { Sub-Saharan } \\
\text { Africa }\end{array}$ & $\begin{array}{c}20.23 \\
(19.00,21.58)\end{array}$ & $\begin{array}{c}17.21 \\
(16.46,18.00)\end{array}$ & $\begin{array}{c}0.73 \\
(0.49,1.03)\end{array}$ & $\begin{array}{c}5.83 \\
(3.99,8.15)\end{array}$ & $\begin{array}{c}47.21 \\
(44.29,50.33)\end{array}$ & $\begin{array}{c}17.07 \\
(16.37,17.86)\end{array}$ & $\begin{array}{c}1.66 \\
(1.12,2.34)\end{array}$ & $\begin{array}{c}5.63 \\
(3.85,7.84)\end{array}$ & $\begin{array}{c}-0.01 \\
(-0.03,0.01)\end{array}$ & $\begin{array}{c}-0.14 \\
(-0.17,-0.11)\end{array}$ \\
\hline $\begin{array}{l}\text { Eastern } \\
\text { Sub-Saharan } \\
\text { Africa }\end{array}$ & $\begin{array}{c}17.97 \\
(16.76,19.31)\end{array}$ & $\begin{array}{c}17.47 \\
(16.60,18.31)\end{array}$ & $\begin{array}{c}0.61 \\
(0.40,0.86)\end{array}$ & $\begin{array}{c}5.58 \\
(3.82,7.87)\end{array}$ & $\begin{array}{c}40.91 \\
(38.25,43.77)\end{array}$ & $\begin{array}{c}17.42 \\
(16.61,18.24)\end{array}$ & $\begin{array}{c}1.29 \\
(0.87,1.84)\end{array}$ & $\begin{array}{c}5.31 \\
(3.65,7.51)\end{array}$ & $\begin{array}{c}0.00 \\
(0.00,0.01)\end{array}$ & $\begin{array}{c}-0.15 \\
(-0.17,-0.14)\end{array}$ \\
\hline $\begin{array}{l}\text { Central } \\
\text { Sub-Saharan } \\
\text { Africa }\end{array}$ & $\begin{array}{c}5.35 \\
(5.02,5.68)\end{array}$ & $\begin{array}{c}17.20 \\
(16.44,17.96)\end{array}$ & $\begin{array}{c}0.18 \\
(0.12,0.25)\end{array}$ & $\begin{array}{c}5.49 \\
(3.78,7.64)\end{array}$ & $\begin{array}{c}12.73 \\
(11.90,13.52)\end{array}$ & $\begin{array}{c}16.76 \\
(15.99,17.50)\end{array}$ & $\begin{array}{c}0.40 \\
(0.27,0.57)\end{array}$ & $\begin{array}{c}5.15 \\
(3.56,7.25)\end{array}$ & $\begin{array}{c}-0.07 \\
(-0.10,-0.05)\end{array}$ & $\begin{array}{c}-0.18 \\
(-0.20,-0.16)\end{array}$ \\
\hline $\begin{array}{l}\text { Southern } \\
\text { Sub-Saharan } \\
\text { Africa }\end{array}$ & $\begin{array}{c}6.39 \\
(6.05,6.77)\end{array}$ & $\begin{array}{c}18.28 \\
(17.49,19.12)\end{array}$ & $\begin{array}{c}0.21 \\
(0.14,0.30)\end{array}$ & $\begin{array}{c}5.92 \\
(4.06,8.30)\end{array}$ & $\begin{array}{c}11.99 \\
(11.43,12.60)\end{array}$ & $\begin{array}{c}18.13 \\
(17.36,18.93)\end{array}$ & $\begin{array}{c}0.37 \\
(0.25,0.52)\end{array}$ & $\begin{array}{c}5.69 \\
(3.92,7.99)\end{array}$ & $\begin{array}{c}-0.02 \\
(-0.02,-0.01)\end{array}$ & $\begin{array}{c}-0.17 \\
(-0.19,-0.16)\end{array}$ \\
\hline
\end{tabular}

